\title{
PODERES PÚBLICOS Y COMPETENCIA. EN BUSCA DEL EFECTO ÚTIL DEL DERECHO DE COMPETENCIA
}

\section{PUBLIC POWER AND COMPETITION LAW. LOOKING FOR EFFICIENCY IN COMPETITION LAW ENFORCEMENT}

\author{
María Pilar Canedo Arrillaga \\ Cátedra Jean Monnet en Derecho Transnacional en la Facultad de Derecho \\ Universidad de Deusto \\ Consejera en la CNMC
}

Recibido: 06.06.2020 / Aceptado: 18.06.2020

DOI: https://doi.org/10.20318/cdt.2020.5609

\begin{abstract}
Resumen: El derecho de la competencia ha experimentado una extraordinaria evolución en los últimos años tratando de conseguir una mayor efectividad en la consecución del objetivo de protección del interés general. Para ello, entre otras vías, se han analizado modos de fiscalizar el papel jugado por los poderes públicos, tanto en sus funciones legislativas como ejecutivas, en la creación, mantenimiento o no retirada de los problemas de competencia en el funcionamiento de la sociedad. Tal control puede realizarse desde diferentes áreas del ordenamiento y, dentro del derecho de la competencia, con herramientas de promoción y defensa. Este estudio analiza la relación entre estas posibles reacciones del ordenamiento y concluye, con una perspectiva de búsqueda de la máxima eficiencia, que la misma debe ser de interdependencia y refuerzo mutuo y no de exclusión.
\end{abstract}

Palabras clave: competencia, promoción, defensa, poderes públicos, buena regulación, bienestar social, administración, impugnación de normas y actos, facilitador.

Abstract: competition law has experienced a dramatic change in former times trying to reach a higher level of effectiveness in protecting general interest. In doing so, it looks for ways to monitor burdens to competition that can be created, maintained or not removed by Public Powers (as policy makers or enforcers). This control can come from different areas of the legal order and, if using a competition law perspective, it can use an advocacy or enforcement approach. This study analyses the relation among all those possible reactions of the legal system and concludes that, looking for efficiency, it must be one of interdependence and mutual reinforcement instead of one of exclusion.

Keywords: competition, advocacy, enforcement, public Powers, better regulation, social welfare, administration, challenge in court of rules and administrative acts, facilitator.

Sumario: I. Introducción. II. La actuación de los poderes públicos. 1. Promoción de la competencia. A) Principios que inspiran la actuación de los poderes públicos. B)Diferentes niveles en la promoción de competencia. 2. Defensa de la Competencia y poderes públicos. A) El concepto de operador económico. B) La intervención en una infracción de una entidad que no interviene en el mercado. La figura del facilitador. C) Un posible análisis de la potestad normativa desde la perspectiva de la defensa de la competencia.III. Sobre la relación entre la Defensa de la competencia y otras reacciones posibles del ordenamiento. 1. Relación entre el Derecho de la competencia y otras áreas del ordenamiento. 2. La relación entre las vías de promoción y defensa de la competencia. A) La solución reciente de las Autoridades de competencia en España. B) Una jurisprudencia no unánime. C) Análisis de las posibles soluciones. IV.Conclusión. 


\section{Introducción}

1. Los poderes públicos, en sentido amplio, cumplen funciones diversas en nuestro ordenamiento que, en numerosas ocasiones generan afectación y merecen por tanto atención desde una perspectiva de competencia.

Una de esas funciones está vinculada con la capacidad del Estado de crear las normas jurídicas que rigen el funcionamiento de nuestra sociedad, especialmente cuando tales normas se encargan de establecer o controlar la operativa de los mercados o de determinados sectores económicos ${ }^{1}$. Por otra parte, las administraciones en sentido amplio tienen, especialmente en Estados Sociales y Democráticos y de Derecho como el nuestro, la relevante labor de prestar servicios a los ciudadanos para garantizar diversos derechos inherentes al mencionado Estado Social.

En ambos supuestos (generación de normas o toma de decisión administrativa) cabe la posibilidad de que se produzcan limitaciones a la competencia que en algunos casos están justificadas, pero en otros pueden no estarlo. El poder público realiza un análisis de diversos intereses en conflicto y puede, justificadamente, considerar que prevalecen valores superiores a la competencia. Tal decisión debe realizarse en todo caso partiendo del parámetro fundamental de protección del interés general y debe ser posible someterlo a control para determinar la adecuación de la decisión adoptada al objetivo pretendido.

La valoración de tales decisiones públicas desde una perspectiva de competencia ha variado a lo largo del tiempo.

2. Históricamente las posibles restricciones en la competencia generadas de cualquier modo por los poderes públicos se consideraban integradas dentro de las prerrogativas que les eran inherentes.

A los entes de carácter público se les presumía la capacidad para realizar la ponderación de todos los intereses en presencia en cada decisión a tomar. Del mismo modo se les presuponía la discrecionalidad para decidir entre las diferentes opciones sin necesidad de realizar justificaciones profundas de las motivaciones que fundaban sus actos. Por ello estas conductas quedaban fuera de las labores de fiscalización de las autoridades de competencia, que se limitaban a la función de defensa de la competencia vinculada al análisis de infracciones generadas por operadores privados.

3. Sin embargo, pronto se mostró la evidencia de que la competencia no solo puede ser afectada, sino que a menudo lo es, por numerosas políticas públicas, por actuaciones institucionales y por intervenciones gubernamentales en los mercados. Por ello, en las primeras décadas de los años 90 se desarrolla una nueva rama de actuación de las autoridades de competencia que les exige incidir de manera más amplia en el análisis de las reglas que rigen la sociedad y los mercados y en la forma en que son aplicadas por las administraciones.

El objetivo de esta actuación es verificar si existen formas de mejorar el funcionamiento de la economía para promover más adecuadamente la protección del interés general por medio del análisis de las actuaciones de carácter público en sentido amplio.

Ese estudio constituye el objeto fundamental de las tareas de promoción de la competencia que, como veremos, emplean como herramienta, esencialmente, decisiones de las autoridades de competencia no vinculantes para los poderes públicos².

La evolución de las labores de fiscalización de la actuación pública ha puesto de manifiesto que la existencia de colaboración en forma de soft law puede no ser suficiente para conseguir los objetivos pretendidos y, en consecuencia, se plantea la posibilidad, no exenta de gran controversia, de incluir a los poderes públicos en procedimientos de defensa de la competencia ${ }^{3}$.

${ }^{1}$ J.De la Cruz Ferrer, Principios de regulación económica en la Unión Europea, en http://www.cerecom.org/publicaciones/LIBRO\%20PRINCIPIOS\%20REGULACI\%C3\%93N\%20CAP\%201.pdf.

2 M.Gracia Montanari, "The ICA's advocacy activity: Proposals for the annual law on competition 2014", en Italian Antitrust Review, Vol. 1, N. 3, 2014, pp. 235 a 240.

${ }^{3}$ Véase, por ejemplo, la Resolución de la CNMC de 26 de julio de 2018, Expte. S/DC/0565/15 LICITACIONES DE APLICACIONES INFORMÁTICAS, en https://www.cnmc.es/expedientes/sdc056515. 
4. Se plantea igualmente la relación entre ambas vías de acción: la defensa y la promoción de la competencia. Esta cuestión ha cobrado especial relevancia debido a una jurisprudencia no unánime a este respecto y a las extraordinarias consecuencias prácticas que, como veremos, podría tener considerar que un poder público no puede ser declarado responsable de infracciones de defensa de la competencia en absoluto o que no puede serlo en los supuestos en que su actuación puede abordarse con herramientas de promoción.

5. La finalidad de este trabajo es hacer un análisis de los objetivos pretendidos por la normativa de promoción y defensa de la competencia en relación con los poderes públicos para justificar la doble conclusión que ya avanzamos. Las conclusiones se plantean ya en este momento para que el lector pueda vislumbrar desde el inicio la razón de ser de la argumentación que se plantean.

La primera hipótesis supone que la vía de la promoción es útil y eficaz para analizar las limitaciones a la competencia de los poderes públicos y puede considerarse imprescindible, pero que puede en algunos casos no ser suficiente para alcanzar los objetivos de protección del bienestar social pretendidos. En algunos casos la vía de defensa, que implica considerar a los poderes públicos responsables de la comisión de infracciones de competencia, es la más o incluso la única vía para conseguir la adecuada protección del interés general.

Esta primera premisa sirve de base a la que será la segunda: considerar que no cabe defensa de la competencia en los supuestos en que pueden realizarse impugnaciones puede resultar contrario al efecto útil del derecho de la competencia y por tanto ambas vías deben necesariamente considerarse herramientas complementarias y en ningún caso excluyentes.

\section{La actuacion de los poderes publicos desde la perspectiva de competencia}

\section{Promoción de la competencia}

6. La promoción de la competencia plantea, entre otras cuestiones, diversas formas de relación entre las autoridades de competencia y los poderes públicos ${ }^{4}$. El objetivo es conseguir que se reduzcan barreras de entrada en los mercados, se promueva la liberalización de los servicios y el comercio y se minimicen las intervenciones innecesarias del Estado en la economía ${ }^{5}$.

Tal relación afecta, como veremos a continuación, a los poderes ejecutivo y legislativo y se basa en principios bien asentados en nuestro ordenamiento.

Los distintos niveles de interacción entre las autoridades de competencia y los poderes públicos difieren en gran medida dependiendo de los objetivos pretendidos y de las situaciones analizadas.

\section{A) Principios que inspiran la acutación de los poderes públicos}

7. La intervención de la administración en la economía está amparada en nuestro ordenamiento jurídico por la propia Constitución Española.

La actuación administrativa se regula en el artículo 103.1 de la Constitución Española que consagra el principio de eficacia y pleno sometimiento de la administración a la Ley y al Derecho. Tal sometimiento se entiende, dentro de la Unión Europea, no solo al Derecho nacional sino a aquellos preceptos del Derecho de la Unión que le resultan de aplicación.

La exigida eficacia en la actuación de la Administración se contiene igualmente en el artículo 41 de la Carta de Derechos Fundamentales de la Unión Europea que recoge el derecho de los ciudadanos a una buena administración.

\footnotetext{
${ }^{4}$ OECD SECRETARIAT, Strategies for Competition Advocacy: Background Paper, DAF/COMP/LACF(2010)4 en http:// www.oecd.org/competition/latinamerica/2010LACF-Strategies-for-competition-advocacy.pdf.

${ }^{5}$ BANCO MUNDIAL, A Framework for the Design and Implementation of Competition Law and Policy, 1998, Capítulo 6.
} 
Dentro de tal sometimiento al Derecho y de la exigencia de eficiencia, el principio de garantía de la libre competencia juega un papel esencial.

8. El control de la actuación de los poderes públicos desde la perspectiva de competencia no se limita a los poderes ejecutivos sino que afecta igualmente a los legislativos.

Para analizar la actuación de los poderes públicos desde la perspectiva de competencia debe partirse de la aplicación de lo que ha venido en denominarse principios de buena regulación (Better Regulation en su denominación inglesa) ${ }^{6}$.

Los mismos, de origen anglosajón, implican que la intervención del Estado en la economía tan solo debe producirse en los supuestos en que la misma resulte necesaria para resolver un fallo de mercado o para proteger lo que la jurisprudencia europea ha dado en denominar Razones de Imperioso Interés General (RIIG). En defecto de ambos, se entiende que el mercado regula de la manera más adecuada su funcionamiento y la intervención estatal puede interferir de manera disfuncional en la asignación adecuada de los recursos.

Sin embargo, cuando exista fallo de mercado o una RIGG, la ausencia de intervención pública genera una respuesta inadecuada del mercado que permite a algunos operadores (por ejemplo los monopolistas) una acumulación excesiva de rentas que resulta contraria al interés de la sociedad.

Estos principios de buena regulación se centran en la identificación del fallo de mercado o la RIGG y analizan la decisión pública (existente o propuesta) que incide negativamente en la competencia desde la perspectiva de verificar si resulta necesaria para proteger el interés general (principio de necesidad), si genera discriminación entre los posibles destinatarios y si, entre todas las medidas posibles de intervención se ha optado por la menos restrictiva (principio de proporcionalidad) ${ }^{7}$.

9. Tales principios fueron considerados por las autoridades de competencia durante años provenientes fundamentalmente de las reglas instauradas de los precedentes de las sentencias del Tribunal de Justicia de la Unión Europea ${ }^{8}$. Son especialmente interesantes las recientes Conclusiones del Abogado General en el asunto Cali Appartments al contener referencia a varios precedentes y una descripción del modo de identificación de una razón imperiosa de interés general y al examen de la proporcionalidad ${ }^{9}$

"Es jurisprudencia asentada que la protección conferida por el artículo 16 de la Carta implica la libertad para ejercer una actividad económica o mercantil ${ }^{10}$.La libertad de empresa no es una prerrogativa absoluta, sino que debe tomarse en consideración atendiendo a su función dentro de la sociedad ${ }^{11}$. Por lo tanto, la libertad de empresa puede estar sometida a un amplio abanico de intervenciones del poder público que establezcan limitaciones al ejercicio de la actividad económica en aras del interés general. En principio, con arreglo al artículo 52, apartado 1, de la Carta, cualquier limitación del ejercicio de los derechos y libertades en ella reconocidos deberá ser establecida por la ley, respetar el contenido esencial de dichos derechos y libertades, respetar el principio de proporcionalidad y responder efectivamente a objetivos de interés general reconocidos por la Unión o a la necesidad de protección de los derechos y libertades de los demás ${ }^{12}$

${ }^{6}$ C. Gómez Asensio, La mejora regulatoria (Better Regulation) Aplicaciones en materia de contratación pública, Ed. Tirant Lo Blanch, Valencia, 2013.

7 OECD, Product Market Regulation OECD PMR Indicators, 2018, en http://www.oecd.org/economy/reform/indicators-of-product-market-regulation.

${ }^{8}$ Véase por ejemplo la Sentencia de 24 de marzo de 2011 del Tribunal de Justicia de la Unión Europea. Asunto C-400-08. Comisión contra España.

${ }^{9}$ Conclusiones del Abogado General Michal Bobek de 2 de abril de 2020, As. C-724/18 y C-727/18, Cali Apartments contra Procureur général près la cour d'appel de Paris, Ville de Paris, de 2 de abril de 2020, ECLI:EU:C:2020:251

${ }_{10}$ Sentencias de 22 de enero de 2013, Sky Österreich (C283/11, EU:C:2013:28), apartado 42; de 17 de octubre de 2013, Schaible (C101/12, EU:C:2013:661), apartado 25; y de 4 de mayo de 2016, Pillbox 38 (C477/14, EU:C:2016:324), apartado155.

${ }^{11}$ Véanse las sentencias de 22 de enero de 2013, Sky Österreich (C283/11, EU:C:2013:28), apartado 45 y la jurisprudencia citada; de 17 de octubre de 2013, Schaible (C101/12, EU:C:2013:661), apartado 28; y de 21 de diciembre de 2016, AGET Iraklis (C201/15, EU:C:2016:972), apartado 85.

${ }^{12}$ Véanse, por ejemplo, las sentencias de 22 de enero de 2013, Sky Österreich (C283/11, EU:C:2013:28), apartados 46 a 48, y de 20 de diciembre de 2017, Polkomtel (C277/16, EU:C:2017:989), apartado 51. 
10. Recientemente estos principios han sido convertidos en norma jurídicamente vinculante para los poderes públicos españoles por medio de la entrada en vigor del artículo 129 de la Ley de Procedimiento Administrativo ${ }^{13}$. El citado precepto, bajo el título Principios de buena regulación, establece que tanto en la iniciativa legislativa como en la reglamentaria, las administraciones deben respetar los principios de "necesidad, eficacia, proporcionalidad, seguridad jurídica, transparencia, y eficiencia".

El legislador español determina no solo que deben respetarse los citados principios, sino que debe realizarse una adecuada motivación por parte del órgano proponente de tal concurrencia.

Tal exigencia de motivación resulta coherente con la posibilidad abierta a los ciudadanos afectados (o a la autoridad de competencia) de controlar que los poderes se ejercen dentro de los márgenes previstos en el ordenamiento (nacional y europeo). Es decir, no existe una potestad absoluta del poder público de definir las RIIG ni determinar los modos de protegerlas sino que recae sobre el órgano proponente una obligación de explicitarlas y acreditar de manera motivada que las limitaciones propuestas sirven a su consecución. De hecho, para conseguir este objetivo el precepto exige que las normas definan claramente sus objetivos y justificación.

La norma establece expresamente que "en virtud de los principios de necesidad y eficacia, la iniciativa normativa debe estar justificada por una razón de interés general, basarse en una identificación clara de los fines perseguidos y ser el instrumento más adecuado para garantizar su consecución". Además "en virtud del principio de proporcionalidad, la iniciativa que se proponga deberá contener la regulación imprescindible para atender la necesidad a cubrir con la norma, tras constatar que no existen otras medidas menos restrictivas de derechos, o que impongan menos obligaciones a los destinatarios"14.

El precepto exige también una garantía adecuada del principio de seguridad jurídica y en consecuencia impone a las iniciativas normativas que sean coherentes con el ordenamiento nacional y europeo de forma que se genere "un marco normativo estable, predecible, integrado, claro y de certidumbre, que facilite su conocimiento y comprensión y, en consecuencia, la actuación y toma de decisiones de las personas y empresas". Además la norma exige que se posibilite el acceso "sencillo, universal y actualizado" a las normas en vigor y los documentos propios de su proceso de elaboración para respetar el principio de transparencia ${ }^{15}$.

En la misma línea de consecución de una adecuada protección del interés general, y yendo más allá de los principios expuestos, la norma establece que las iniciativas normativas deben evitar la "imposición de cargas administrativas innecesarias o accesorias y racionalizar, en su aplicación, la gestión de los recursos públicos" en aplicación del principio de eficiencia.

Por primera vez en el ordenamiento español se establece la exigencia de que cuando una norma afecte a "los gastos o ingresos públicos presentes o futuros, se deberán cuantificar y valorar sus repercusiones y efectos y supeditarse al cumplimiento de los principios de estabilidad presupuestaria y sostenibilidad financiera".

11. Este precepto ha sido declarado parcialmente contrario al orden constitucional por considerar que invade competencias que las comunidades autónomas "tienen estatutariamente atribuidas en orden a organizarse y regular la elaboración de sus leyes". Por ello determina el Tribunal Constitucional que el precepto no resulta aplicable a las iniciativas legislativas de las Comunidades Autónomas ${ }^{16}$.

${ }^{13}$ Ley 39/2015, de 1 de octubre, del Procedimiento Administrativo Común de las Administraciones Públicas. BOE nº 236, de 2 de octubre de 2015. BOE-A-2015-10565.

${ }^{14}$ Las mismas exigencias se subrayan por la Comisión Europea en ejemplos como EUROPEAN COMMISSION, Study on the Assessment of the Regulatory Aspects Affecting the Collaborative Economy in the Tourism Accommodation Sector in the 28 Member States (580/PP/GRO/IMA/15/15111J) en https://op.europa.eu/en/publication-detail/-/publication/c7a7b5bb-526d11e8-be1d-01aa75ed71a1/language-en/format-PDF.

${ }^{15}$ Ley 4/2007, de 3 de abril, de transparencia de las relaciones financieras entre las Administraciones públicas y las empresas públicas, y de transparencia financiera de determinadas empresas, BOE ${ }^{\circ} 81$, de 4 de abril de 2007.

${ }_{16}$ Véanse la Sentencia del Tribunal Constitucional 55/2018, de 24 de mayo de 2018. Recurso de inconstitucionalidad 3628-2016. Interpuesto por el Gobierno de la Generalitat de Cataluña en relación con diversos preceptos de la Ley 39/2015, de 1 de octubre, del procedimiento administrativo común de las administraciones públicas. Competencias sobre procedimiento administrativo: nulidad de diversos extremos de los preceptos relativos a los registros electrónicos de apoderamientos, los principios de buena regulación y que identifican los títulos competenciales habilitantes para la aprobación de la ley; inconstitucionalidad de distintos preceptos que regulan la iniciativa legislativa y la potestad reglamentaria; interpretación conforme 
Es decir, el Tribunal no cuestiona que los mismos principios deban ser respetados por el legislador autonómico, sino que tan solo determina que el legislador estatal no puede establecer tales imposiciones a los autonómicos.

\section{B) Diferentes niveles en la promoción de la competencia}

12. Las tareas de promoción de la competencia en relación con los poderes públicos comenzaron realizándose de modo informal por medio de contactos entre las entidades encargadas de las tomas de decisión y quienes deben velar por el respeto a los principios de competencia. Sin embargo, las exigencias de transparencia, independencia y control de las autoridades de competencia pronto hicieron evidente que resulta necesario que las colaboraciones entre los poderes públicos y las autoridades de competencia se arbitren por cauces más formales ${ }^{17}$.

De este modo, las autoridades de competencia nacionales más avanzadas del mundo comienzan a crear direcciones de promoción de la competencia con el mismo nivel de relevancia y jerarquía que las direcciones de instrucción en materia de defensa ${ }^{18}$.

En España la Ley 15/2007 introduce por primera vez referencias a la promoción de la Competencia y la CNC crea una Dirección de promoción de la competencia adaptándose a las mencionadas corrientes internacionales ${ }^{19}$.

13. Las direcciones de promoción son encargadas del estudio general del funcionamiento de los mercados con el fin de poder realizar, basándose en datos técnicos e independientes, una evaluación de políticas públicas, de sectores económicos, de propuestas de normas o de acciones de las administraciones. Se trata de este modo de ofrecer a los poderes públicos análisis independientes de los ámbitos en los que sería beneficioso para la sociedad acometer cambios normativos, o de facilitar herramientas para la toma de decisión en procedimientos ya comenzados ${ }^{20}$.

Del mismo modo, cabe que de tales análisis se derive la convicción de que existe una decisión del poder público ya adoptada que resulte contraria a la competencia en cuyo caso el mero asesoramiento no resulta suficiente y puede considerarse necesario otro tipo de intervención para remover los obstáculos y favorecer el bienestar social.

\section{a) Herramientas de promoción destinadas a ofrecer asesoramiento técnnico a los poderes públicos}

14. Varias son las herramientas fundamentales de trabajo en la promoción de la competencia y tienen objetivos, metodologías y procedimientos de elaboración muy diferentes. De hecho, muchas

de la disposición relativa a la adhesión de las administraciones territoriales a las plataformas y registros de la Administración General del Estado. Voto particular. BOE núm. 151, de 22 de junio de 2018, pp 63925 a 63967, (ECLI:ES:TC:2018:55) y la Sentencia del Tribunal Constitucional 50/1999, de 6 de abril de 1999. Recursos de inconstitucionalidad 521/1993 y 547/1993 (acumulados). Promovidos, respectivamente, por la Junta de Castilla y León y por el Consejo Ejecutivo de la Generalidad de Cataluña contra determinados preceptos de la Ley 30/1992, de 26 de noviembre, de Régimen Jurídico de las Administraciones Públicas y del Procedimiento Administrativo Común. Voto Particular, BOE núm. 100, de 27 de abril de 1999, pp. 85 a 95.FFJJ 7 y 8.

${ }^{17}$ H. Bouthinon-Dumas/ V. De Beaudort/ F. Jenny/ A.Masson, Stratégies d'instrumentalisation juridique et concurrence. Larcier. Bruxelles, 2013.

${ }^{18}$ Véase ADVOCACY WORKING GROUP ICN Advocacy and Competition Policy Naples, Italy, 2002 en https://www. internationalcompetitionnetwork.org/wp-content/uploads/2018/09/AWG_AdvocacyReport2002.pdf.

${ }^{19}$ Ley 15/2007, de 3 de julio, de Defensa de la Competencia, BOE $n^{-} 159$, de 4 de julio de 2007. Texto consolidado https:// www.boe.es/buscar/act.php?id=BOE-A-2007-12946.

${ }^{20}$ OCDE, "Key points of the Roundtables on Changes in Institutional Design" in Draft Summary Record: Annex to the summary record of the 123rd meeting of the Competition Committee held on 15 - 19 June 2015. 29 January 2016. DAF/COM$\mathrm{P} / \mathrm{M}(2015) 1 / \mathrm{ANN} 9$, en http://www.oecd.org/officialdocuments/publicdisplaydocumentpdf/?cote=DAF/COMP/M(2015)1/ANN9\&doclanguage $=$ en 
veces se define la promoción de la competencia de manera negativa como todas aquellas medidas que fomentan la competencia y no pueden considerarse defensa ${ }^{21}$.

15. Los estudios de mercado o informes sectoriales suponen la realización de "un análisis económico y regulatorio exhaustivo que analiza en profundidad la dinámica de la competencia en un mercado o sector productivo, identificando las restricciones existentes en dicho mercado que dificultan o impiden una asignación eficiente de los recursos. El Estudio alcanza conclusiones y propone recomendaciones para paliar o eliminar dichas restricciones" 22 .

En los estudios, las autoridades de competencia toman la decisión independiente de analizar mercados en que pueden estar produciéndose problemas o disfunciones. Se trata de verificar si las normas que los regulan pueden estar contribuyendo a frenar esos problemas o paliarlos o, por el contrario, contribuyen a que se incrementen los efectos negativos en la sociedad generando barreras injustificadas de entrada o salida del mercado o de ejercicio para los operadores ya instalados.

El hecho de que los estudios supongan una decisión autónoma de la autoridad de competencia hace que no estén sometidos a plazos por lo que su nivel de profundidad puede ser mayor (y en consecuencia también su valor). Además la selección de temas el número de informes que se publiquen (junto evidentemente con el impacto que puedan tener) son una forma de evaluar a la autoridad que los realiza.

16. Las autoridades de competencia realizan guías de divulgación de la cultura de competencia y buena regulación entre poderes públicos, empresas, consumidores y otros entes interesados, indicando -de manera adaptada a los destinatarios- modos de conseguir una adecuada garantía del interés general por la vía de la inclusión de los principios de competencia en las diferentes tomas de decisión ${ }^{23}$.

Del mismo modo, fundamentalmente dentro de la Unión Europea, realizan análisis de la actuación del Estado en materia de ayudas públicas y su incidencia en el mercado y la neutralidad competitiva ${ }^{24}$.

17. Los informes de proyectos normativos son análisis a petición de parte que tienen ordinariamente plazos cortos y exigen una respuesta ágil y en ocasiones puede que, en consecuencia, menos profunda. De ello no puede sin embargo deducirse que tengan necesariamente menor valor, dado que su inmediatez puede precisamente permitir ver su eficacia de manera más rápida.

El objetivo de la autoridad de competencia es ofrecer al poder público un análisis de los efectos que la norma propuesta puede tener en el mercado para enriquecer el análisis llevado a cabo por el órgano proponente. Se trata de incluir en la reflexión un estudio de los efectos que pueden tener las medidas propuestas. Muchas veces los efectos en el mercado de determinadas medidas resultan tangenciales de los objetivos realmente buscados y quien realiza la propuesta puede no ser consciente de las implicaciones negativas que pueden tener sus decisiones. En esos supuestos la colaboración de la autoridad de competencia podría ayudar a reconsiderar determinadas medidas por innecesarias.

Otras veces, cierta restricción es necesaria para alcanzar el objetivo pretendido por el legislador pero el mismo puede ser alcanzado por vías diferentes que tienen menos efectos negativos en el mercado.

En algunos casos las medidas propuestas generan discriminación entre los afectados por la norma.

Todas estas cuestiones pueden ser puestas de manifiesto por la autoridad de competencia durante la tramitación de la norma jurídica lo que puede llevar al poder público a modificar el contenido de

\footnotetext{
${ }^{21}$ OCDE, Competition advocacy: challenges for developing countries, en http://www.oecd.org/daf/competition/prosecutionandlawenforcement/32033710.pdf.

${ }_{22}$ A.Maudes, Metodología para la elaboración de Estudios de Mercado en la CNMC, Madrid, octubre 2013, MET/ DP/01/13, en https://www.cnmc.es/file/126383/download.

${ }^{23}$ Véase CNMC, Guías, en https://www.cnmc.es/ambitos-de-actuacion/promocion-de-la-competencia/guias.

${ }^{24}$ Véase CNMC, Ayudas Públicas, en https://www.cnmc.es/ambitos-de-actuacion/promocion-de-la-competencia/ayudas-publicas; OECD, "Executive Summary of the Discussion of the Roundtable on Competitive Neutrality in Competition Policy" in Draft Summary Record: Annex to the summary record of the 123rd meeting of the Competition Committee held on 15 - 19 June 2015. 29 January 2016. DAF/COMP/M(2015)1/ANN7, en http://www.oecd.org/officialdocuments/publicdispla ydocumentpdf/?cote=DAF/COMP/M\%282015\%291/ANN7\&doclanguage=en, y COMISION EUROPEA, Ayudas de Estado https://ec.europa.eu/info/live-work-travel-eu/health/coronavirus-response/jobs-and-economy-during-coronavirus-pandemic/ state-aid-cases_es.
} 
la propuesta de forma que se reconsideren sus objetivos o, sin hacerlo, se diseñen nuevas herramientas menos restrictivas para lograrlos.

18. Del mismo modo cabe que la autoridad de competencia analice, bajo los parámetros referidos, normas ya existentes (en los ordinariamente denominados informes de posición).

Este es el caso, no inhabitual, de normas que se crean en determinadas circunstancias socioeconómicas que son objeto de modificación por la evolución social sin que el ordenamiento jurídico experimente cambios equivalentes. Ello puede tener como consecuencia que restricciones que tuvieron su razón de ser en determinados momentos históricos dejen de tenerla y comiencen a crear distorsiones carentes de fundamento.

En estos supuestos las autoridades de competencia tienen la potestad de realizar informes dirigidos a los poderes públicos y a la sociedad lo que puede contribuir a cambios normativos que supongan la remoción de obstáculos innecesarios de manera que se potencie la protección del interés general.

19. En cualquier caso no podría concluirse que la eficacia de un análisis de los tipos anteriores se limite a su efecto directo e inmediato en una modificación de la actuación del órgano proponente ${ }^{25}$.

Una de las labores de promoción de la competencia es, precisamente, contribuir al desarrollo de una conciencia social sobre las ventajas que la competencia genera en los más desfavorecidos de la sociedad. Tal ventaja se verifica fundamentalmente en forma de mejores precios que permiten acceder a más y mejores productos y servicios democratizando el acceso a ellos; puede observarse también en forma de mayores posibilidades de elección, de más innovación, de creación de empleo, de reducción de las ventajas no merecidas que han podido tener determinados operadores solo por ser los tradicionales o vinculados con el poder. Indirectamente, se generan ventajas de competitividad de la economía y en consecuencia de mejores condiciones de vida para la sociedad.

El hecho de que las autoridades de competencia realicen y publiquen sus informes basados en datos (que puedan rebatir los ofrecidos a menudo por los lobbies empresariales) ayuda a generar esa conciencia que puede producir efectos positivos en la conciencia social a medio plazo.

\section{b) Las funciones de impugnación}

20. Dentro de las tareas de promoción, la cooperación con los poderes públicos se complementa en algunos ordenamientos, como el español, por una labor de fiscalización por las autoridades de competencia de las actuaciones realizadas por los poderes públicos que va más allá de la mera colaboración.

De esta forma, identificadas barreras o trabas injustificadas generadas por los poderes públicos, sea en el ámbito de la regulación o de la actuación administrativa, éstas pudieran suprimirse del ordenamiento por medio de su impugnación ${ }^{26}$.

Esta función resulta crucial para evitar que se generen problemas en los mercados que resultan negativos para el interés de las empresas y los ciudadanos o en última instancia de la sociedad no solo por las limitaciones a la competencia a que se pone fin gracias a la actuación de los tribunales, sino incluso por las restricciones que no llegan a crearse por los poderes públicos, conscientes del riesgo de impugnación de sus decisiones ${ }^{27}$. Es decir, esta función no solo tiene implicaciones de reparación sino que incluso tiene un efecto de prevención.

${ }^{25}$ J.HILKE, Improving relationships between competition policy and sectoral regulation, 2006 en http://www.oecd.org/daf/ competition/prosecutionandlawenforcement/38819635.pdf.

26 J.GuILlÉn CARAMÉs, "La promoción de la competencia como refuerzo al ejercicio de potestad sancionadora por parte de las autoridades de competencia : en especial, la impugnación de la actividad administrativa contraria al Derecho de la Competencia" en Cuestiones actuales del procedimiento sancionador en Derecho de la Competencia, capitulo VI La impugnación por las Autoridades de Competencia de la actuación de las Administraciones Públicas. Ed. Civitas, D.L. 2013, pp. 369 a 399.

27 A.Tonazzi/M.Pacillo, "Some thoughts on "Advocacy: a driver for change”, ICN Workshop, 12-13 December 2013, Rome", en Italian Antitrust Review, Vol. 1, N. 1, 2014, pp. 111 a 113. 
21. El ordenamiento jurídico español establece que la autoridad de competencia en cumplimiento de sus funciones, "está legitimada para impugnar ante la jurisdicción competente los actos de las Administraciones Públicas sujetos al Derecho administrativo y disposiciones generales de rango inferior a la ley de los que se deriven obstáculos al mantenimiento de una competencia efectiva en los mercados"28.

Tal capacidad supone que, más allá de la cooperación, la autoridad de competencia puede solicitar del poder judicial que ponga fin a las restricciones a la competencia generadas por los poderes públicos en aras de conseguir un incremento en los estándares de protección del interés general.

22. La capacidad de impugnación, incluida en nuestro ordenamiento en el año 2007, se enfrentó a importantes dificultades de interpretación derivadas en parte del escaso desarrollo normativo y en parte del enfrentamiento que esta potestad supone a la tradicional autonomía de los poderes públicos para ejercer sus prerrogativas con un amplio margen de discrecionalidad para alcanzar los objetivos pretendidos por la vía que se considerara más adecuada y sin grandes exigencias de motivación.

La aprobación de normas como el artículo 129 de la LPA vienen a aclarar las exigencias de las administraciones y en consecuencia a facilitar la tarea de la autoridad de competencia no exenta, sin embargo, de dificultades de interpretación.

23. Nuestro legislador no ha reconocido a las autoridades de competencia legitimación activa para plantear la constitucionalidad de las normas jurídicas ante el TC.

Sin embargo el Derecho de la Unión Europea exige que se inapliquen las normas internas que no respetan sus principios esenciales ${ }^{29}$.

Por ello, nada obstaría a que la autoridad de competencia impugnara las normas internas de cualquier rango contrarias a la competencia, siempre que contravengan el Derecho de la Unión. En caso de duda el tribunal interno podría solicitar la interpretación del Tribunal de Justicia por medio de la presentación de una cuestión prejudicial.

Por el contrario, en el caso de que se trate de normas con rango de Ley que no generen controversia con el derecho de la Unión, la labor de la autoridad de competencia se limita a la promoción soft. La misma tomaría la forma de mera colaboración por medio de la realización de informes (no vinculantes) que tratan de aportar al proponente de una norma nueva, o al responsable de una existente, razones que le lleven a modificar su posición. No sería posible la impugnación.

24. De cualquier modo, en el caso de normas con rango inferior a la Ley o de actos de la administración pública, la normativa española permite la impugnación siguiendo los tramites procesales correspondientes.

El artículo 44.1 de la Ley de la Jurisdicción establece que, cuando una Administración interponga recurso contencioso-administrativo contra otra, podrá requerirle previamente para que derogue la disposición o anule o revoque el acto en cuestión ${ }^{30}$.

El requerimiento deberá producirse en el plazo de dos meses contados desde la publicación de la norma o desde que la Administración requirente hubiera conocido o podido conocer el acto (párrafo 2) salvo lo dispuesto en la legislación de régimen local (párrafo 4) que establece el plazo de un mes ${ }^{31}$.

25. Estos plazos tan escasos desde que se adopta la norma o el acto administrativo suponen una extraordinaria limitación a la capacidad de impugnación de las autoridades de competencia.

28 Véase el artículo 5.4 de la Ley 3/2013, de 4 de junio, de creación de la Comisión Nacional de los Mercados y la Competencia, BOE $\mathrm{n}^{\mathrm{0}} 134$, de 5 de junio de 2013 y artículo 13.2 de la citada LDC para las autoridades autonómicas.

${ }^{29}$ Véase el leading case Sentencia del TJUE de 22 de junio de 1989, Fratelli Constanzo, SpA, As. 103/88, ECLI:EU:C:1989:256 y sus muchas confirmaciones posteriores Sentencia del Tribunal de Justicia de 14 de septiembre de 2017, As. C-628/15, The Trustees of the BT Pension Scheme y Commissioners for Her Majesty's Revenue and Customs, ECLI:EU:C:2017:687.

Dentro del ordenamiento interno, véase la Sentencia del Tribunal Constitucional 140/2018, de 20 de diciembre, BOE núm. 22, de 25 de enero de 2019, ECLI:ES:TC:2018:140.

${ }^{30}$ Ley 29/1998, de 13 de julio, reguladora de la Jurisdicción Contencioso-administrativa, BOE no 167, de 14 de julio de 1998.

${ }^{31}$ Véase el artículo 65 de la Ley 7/1985, de 2 de abril, Reguladora de las Bases del Régimen Local. 
La evidencia demuestra que en la mayoría de casos cuando se detectan las restricciones a la competencia que puede suponer la actuación pública tales plazos ya han transcurrido y por tanto, de no arbitrarse medios alternativos para reevaluar las medidas, los problemas de competencia pueden dilatarse en el tiempo de manera no acorde con la exigida protección del bienestar social.

\section{c) El caso específico de la contratación pública}

26. Uno de los ámbitos en que con más intensidad se han producido labores de promoción de la competencia en relación con los poderes públicos es la contratación administrativa ${ }^{32}$.

27. Sin entrar en disfunciones en la contratación que pueden resultar ajenas a la competencia (como pueden ser sin duda las que implican supuestos de corrupción) la contratación pública se desarrolló históricamente bajo parámetros en que no se tenían en cuenta, al menos de manera expresa, las ventajas que se derivan de la existencia de competencia entre oferentes en los contratos ${ }^{33}$. De este modo, se primaba la seguridad con que la administración podía llevar a cabo los procesos de contratación, la rapidez o incluso la comodidad de los poderes adjudicadores, frente a la posibilidad de incrementar la calidad de los servicios recibidos, la innovación, la entrada de nuevos operadores o el precio ${ }^{34}$.

La gravedad de esta cuestión y sus negativos efectos para el bienestar de la sociedad comenzó a ponerse de manifiesto por organizaciones internacionales ${ }^{35}$. Especialmente importante es la contribución de la OCDE que subrayó que la existencia de conductas colusorias de las empresas relacionadas con la contratación pública podía suponer un grave quebranto para el interés general en las sociedades en que tales conductas se producían e hizo hincapié en el diseño de mecanismos para tratar de frenarlas ${ }^{36}$.

De ahí que la mayoría de autoridades de competencia del mundo dedicaran gran parte de su capacidad de promoción a hacer conscientes a las administraciones de que tales conductas debían ser evitadas y a fomentar la colaboración entre autoridades de competencia y poderes adjudicadores para contribuir a tal $\mathrm{fin}^{37}$.

28. La existencia de conductas de colusión entre operadores privados en relación con la contratación pública analizados desde la perspectiva clásica de la defensa de la competencia (o bid rigging) dejaba de lado las posibles responsabilidades de la administración en la conducta ${ }^{38}$. Sin embargo pronto se pudo verificar que la administración podía jugar en las citadas prácticas diversos papeles (más o menos activos) pero dignos de atención.

Resulta innegable que en muchos supuestos la administración contratante carece de posibilidad de conocer la existencia de un acuerdo entre las empresas que presentan ofertas .Sería el caso, por ejemplo, de acuerdos sofisticados de reparto de licitaciones de varias administraciones entre un grupo de empresas con prácticas de subcontrataciones entre ellas, compensaciones secretas o boicots, rotaciones,

${ }^{32}$ S.Arrowsmith/P. Kunzlik (Eds), Social and Environmental Policies in EC Procurement Law. New Directives and New Directions Cambridge, Cambridge University Press, 2009.

${ }^{33}$ C.CABanes/ B.Neveu, Droit de la concurrence dans les contrats publics. Pratiques anticoncurrentielles, abus de position dominante, controls et sanctions, Paris, Le Moniteur, 2008.

${ }^{34}$ F.JimÉnez La Torre/ J.Coronado SALEh, "Análisis económico de la colusión en mercados de subastas: pujas fraudulentas (Bid rigging)", en S.Martínez lage/ A.Petibó Juan, (Dirs), Los acuerdos horizontales entre empresas, Ed. Marcial Pons, Madrid, 2009, págs. 213 a 242.

${ }^{35}$ C.De Konick/ P.Flamey(Eds.), European Public Procurement Law. Part II: Remedies. The European Public Procurement Directives and 15 years of Jurisprudence of the Court of Justice of the European Communities - Texts and Analysis, The Hague, Kluwer Law International, 2009.

${ }^{36}$ OCDE, Lineamientos de la OCDE para combatir la colusión entre oferentes en contrataciones públicas, París, 2009. [DAF/COMP(2009)1/FINAL]. Accesible en http://www.oecd.org/daf/competition/Recommendation_fighting-bid-rigging2012-ES.pdf.

${ }^{37}$ R.C.Marshat/L.M. Marx, The economics of Collusion. Cartels and Bid rigging, The MIT Press, Massachusetts, 2012.

${ }^{38}$ M.P.CAnedo Arrillaga, "Algunas consideraciones jurídicas en torno a prácticas de «Bid Rigging»", en Gaceta Jurídica de la Unión Europea y de la Competencia, nº 36, 2013, pp. 9-19. 
ofertas de cobertura.... Existen otros muchos casos, sin embargo, en que no puede llegarse a la misma conclusión y el poder adjudicador puede tener una responsabilidad por acción o por omisión ${ }^{39}$.

Por ello las autoridades de competencia comenzaron, empleando herramientas de asesoramiento técnico, realizando guías de promoción de la competencia que ponían el foco en determinados indicios que podrían despertar en los órganos de contratación la intuición de que alguna conducta contraria a derecho podría estarse produciendo. En ese caso se animaba a las autoridades contratantes a realizar colaboraciones informales con las autoridades de competencia para que estas analizaran la solvencia de tales indicios ${ }^{40}$.

Estos documentos -generales (guías) o referidos a pliegos concretos de contratación (informes concretos)- hacían hincapié en que la actuación de los poderes públicos que también puede generar problemas de competencia ${ }^{41}$. Por ejemplo, la selección de unos procedimientos de contratación frente a otros que genera clara incidencia en el resultado de la contratación. La existencia de procedimientos abiertos y transparentes abre la posibilidad de que todo operador capacitado pueda presentar sus ofertas. Ello genera la adecuada tensión competitiva que induce mejoras de calidad, innovación y precio que son inherentes a la incertidumbre en el resultado de la selección. Lo mismo sucede con la generación y tipo de lotes; el favorecimiento de entrada de PYMES; la publicidad de los contratos; los plazos de presentación de ofertas; las exigencias concretas incluidas en los pliegos de contratación; la adaptación de las exigencias a los objetivos del contrato y la desaparición de exigencias concretas obtenidas de la copia de otros pliegos o tendentes a dirigir la selección a los operadores incumbentes o a algunos preseleccionados por razones diferentes a las publicadas... Todo ello deviene fundamental en la reflexión de los poderes adjudicadores ${ }^{42}$.

29 Se comienza igualmente a cuestionar la regulación de contratación pública desde la perspectiva de competencia para plantearse los problemas que genera, por ejemplo, la existencia de contratos de extraordinaria duración, de prórrogas, de modificaciones o de requisitos no proporcionales al objetivo pretendido o directamente no relacionados con el mismo. Todo ello sucede, en buena medida, de la mano de las exigencias de la $\mathrm{UE}^{43}$.

Por su parte el artículo 132 de la LCSP establece los principios que deben regir los procesos de contratación y afirma que "los órganos de contratación darán a los licitadores y candidatos un tratamiento igualitario y no discriminatorio y ajustarán su actuación a los principios de transparencia y proporcionalidad". Estos principios esenciales a la competencia se explicitan en la afirmación expresa de que no cabe limitar la participación en una contratación por la forma jurídica o el ánimo de lucro en la contratación, salvo en los casos de contratos reservados para ciertas entidades ${ }^{44}$.

El precepto realiza una afirmación de la máxima trascendencia consistente en que la contratación no puede ser concebida por el poder adjudicador "con la intención de eludir los requisitos de publicidad o los relativos al procedimiento de adjudicación que corresponda, ni de restringir artificialmente la competencia, bien favoreciendo o perjudicando indebidamente a determinados empresarios".

Por otra parte se establece expresamente la obligación de los órganos de contratación de velar en todo el procedimiento por la salvaguarda de la libre competencia. Todos los órganos de contratación, la Junta Consultiva de Contratación Pública del Estado o los equivalentes autonómicos tienen la obligación de remitir a las autoridades de competencia los hechos de los que tengan conocimiento y que puedan constituir infracción a la legislación de defensa de la competencia ${ }^{45}$.

${ }^{39}$ F.Marcos Fernández, "Las prohibiciones de prácticas anticompetitivas (TFUE y LDC) ¿es infractor quien facilita la comisión de las conductas prohibidas? en Anuario de la competencia, No 1, 2016,pp.381-413.

${ }^{40}$ A.SÁnchez Graells, Public Procurement and the EU Competition Rules, 2nd ed Oxford, Hart Publishing, 2012.

${ }^{41}$ Véase por ejemplo IPN 068/11: Proyecto de Real Decreto por el que se modifica la letra d- de la cláusula 8 del pliego de cláusulas generales para la construcción conservación y explotación de autopistas en régimen de concesión aprobado por el decreto 215/1973 de 25 de enero en https://www.cnmc.es/expedientes/ipn-06811.

${ }^{42}$ F. Marcos FernándeZ "¿Puede sancionarse a las Administraciones Públicas cuando no actúan como operador económico si restringen la competencia o promueven conductas anticompetitivas?" en Indret: Revista para el Análisis del Derecho,ISSNe1698-739X, No ${ }^{\circ} .1,2018$.

${ }_{43}$ Véase EUROPEAN COMMISSION, Public Procurement, en https://ec.europa.eu/growth/single-market/public-procurement_en.

${ }^{44}$ Lo que se refiere a las recogidas en la disposición adicional cuarta.

${ }^{45}$ Véase igualmente el artículo 150 , pendiente de desarrollo reglamentario, que establece que los órganos de contratación 
30. Las citadas normas, en relación con todas las anteriores, no dejan lugar a duda sobre la posibilidad que se abre a la autoridad de competencia para impugnar ante los tribunales las decisiones referidas a la contratación que generen problemas de competencia.

Las limitaciones a la competencia pueden producirse por inclusión en los pliegos de exigencias no relacionadas con el objeto del contrato, por generación de discriminación, cierre de mercado o cualquier otra limitación a la competencia carente de justificación desde la perspectiva de los principios de necesidad o proporcionalidad.

Dentro del margen de apreciación de los poderes adjudicadores, lo mismo podría llegar a decirse de las decisiones de los poderes adjudicadores en favor de determinados tipos de contratación no favorables a la competencia (como es por antonomasia el procedimiento abierto) cuando la opción no encuentre justificación en la protección del interés general.

\section{Defensa de la Competencia y poderes públicos}

31. Como hemos reflejado, la promoción de la competencia abrió una primera vía para analizar las actuaciones de los poderes públicos desde una perspectiva de competencia. Sin embargo, pronto se puso de manifiesto que en algunos casos la labor de los poderes públicos genera una incidencia en el mercado en que las herramientas de promoción (incluso incluyendo la impugnación) pueden resultar insuficientes para restituir las condiciones de competencia en un mercado.

Por ello se plantea la posibilidad de fiscalizar ciertas actuaciones de los poderes públicos bajo el prisma estricto de la Ley de Defensa de la Competencia. Es decir, se trata de analizar en qué medida un poder público puede ser considerado responsable de una conducta de cártel, de abuso de posición de dominio o de competencia desleal con afectación al interés general (tipos contenidos en los artículos 1 , 2 y 3 de la LDC).

No cabe en este momento poner en duda que el ejercicio de una potestad pública no exime a la administración del cumplimiento de la legalidad y, en consecuencia, de la aplicación de las normas de defensa de la competencia ${ }^{46}$. Se plantea sin embargo cuál es la posible y la más eficiente reacción ante posibles conductas que no respeten tal regulación.

32. Obviamente existe una clara diferencia entre la fiscalización de la capacidad legislativa y de la ejecutiva de los poderse públicos y las diferentes funciones jugadas por el poder público en cada supuesto analizado.

Para realizar el análisis debe considerarse que los poderes públicos operan en los mercados directamente en algunas ocasiones pero que en un muy elevado número de casos inciden en su funcionamiento sin operar en el mismo.

Procede por tanto comenzar analizando si un poder público puede ser sujeto de una infracción de competencia. Posteriormente debe analizarse si el hecho de que el poder público no opere en el mercado supone o no un límite a la aplicación de la normativa defensa de la competencia o si en este ámbito del derecho administrativo sancionador caben figuras diferentes de la autoría.

\section{A) El concepto de operador económico}

33. Las infracciones que constituyen la base de la normativa de defensa de la competencia se definen habitualmente en referencia a los operadores económicos que las llevan a cabo. Tanto la normativa

\footnotetext{
deben trasladar los indicios fundados de conductas colusorias en el procedimiento de contratación la autoridad de competencia con carácter previo a la adjudicación del contrato, a efectos de que a través de un procedimiento sumarísimo se pronuncie sobre aquellos.

${ }^{46}$ E.Navarro Varona/M.Rambal, "La aplicación de las normas de defensa de la competencia a las Administraciones Públicas que no actúan como operadores económicos en el mercado" en Gaceta Jurídica de la Unión Europea y de la competencia, $\mathrm{n}^{\mathrm{o}} 31,2013$, pág. 23 a 34.
} 
nacional como la europea definen los tipos empleando el término "empresa" al referirse a los sujetos, lo cual parecería excluir a los poderes públicos de tal capacidad.

Bajo esta interpretación la defensa de la competencia quedaría limitada a los operadores privados y el control de las tareas de las administraciones u otros poderes públicos quedaría reducido a las herramientas de promoción.

34. Sin embargo, de cara a la aplicación de la normativa de defensa de la competencia la jurisprudencia ha ido perfilando un concepto autónomo de operador económico cuya definición es extraordinariamente amplia para no dejar fuera conductas nocivas para la sociedad. De este modo se entiende que es operador económico a efectos de aplicar la normativa de defensa de la competencia cualquier entidad que ejerza cualquier actividad de trascendencia económica con independencia de su estatuto jurídico y de su modo de financiación.

El Tribunal de Justicia de la Unión Europea manifiesta, en su Sentencia EasyPay and Finance Engineering (ap. 37) ${ }^{47}$ :

"A este respecto procede señalar, en una primera fase, que, por un lado, a efectos de aplicación de las disposiciones del Derecho de la Unión en materia de competencia, una empresa es cualquier entidad que ejerza una actividad económica, con independencia del estatuto jurídico de dicha entidad y de su modo de financiación. Por otro lado, constituye una actividad económica cualquier actividad consistente en ofrecer bienes o servicios en un determinado mercado (véase la sentencia Compass-Datenbank, C138/11, EU:C:2012:449, apartado 35)"48.

En el mismo sentido, el Tribunal Supremo ha establecido que "en el ámbito del Derecho de la competencia opera un concepto amplio y funcional de empresa, de manera que lo relevante no es el estatus jurídico económico del sujeto que realiza la conducta sino que su conducta haya causado o sea apta para causar un resultado económicamente dañoso o restrictivo de la competencia en el mercado"49.

35. Surge entonces la cuestión de si los poderes públicos, en la personificación correspondiente en cada caso, pueden o no considerarse operador económico.

Pocas dudas pueden surgir al respecto cuando, en cumplimiento de las funciones que le son propias, una administración abre un procedimiento de contratación pública que permite a operadores económicos que compiten en el mercado realizar ofertas para conseguir su selección con vistas a prestar el citado servicio. Parece indudable que la administración en ese caso puede considerarse una entidad que ejerce actividad económica y al determinar las condiciones en que tal contratación se desarrolla incide directamente en el mercado.

La competencia es, precisamente, uno de los principios que la Ley considera que debe inspirar el proceso de contratación y la administración tiene la obligación de ser garante de su respeto. No en vano, el artículo 1 de la Ley de contratos, que establece el objeto y finalidad de la Ley, mantiene que la misma debe garantizar los principios de libertad de acceso a las licitaciones; publicidad y transparencia de los pro-

\footnotetext{
${ }^{47}$ Sentencia del Tribunal de Justicia de 22 de octubre de 2015 Asunto C-185/14 (ECLI:EU:C:2015:716).

${ }^{48}$ La misma sentencia establece que «para rechazar la calificación de actividad económica, la mencionada actividad debe formar parte indisociable, por su naturaleza, por su objeto y por las normas a las que está sujeta, del sistema nacional de pensiones de jubilación (véase, por analogía, la sentencia Aéroports de Paris/Comisión, C82/01 P, EU:C:2002:617, apartado 81)» indisolubilidad que no se verifica en el caso analizado.

Véase, entre otras, la Sentencia del Tribunal de Justicia de 1 de julio de 2010, Asunto Knauf Gips KG v Commission, C-407/08 P, ECLI:EU:C:2010:389 o las sentencias del TJUE de 12 de julio de 2012, As. C-138/11 Compass-Datenbank, ECLI:EU:C:2012:449 y de 28 de febrero de 2013, As. C-1/12,Ordem dos Técnicos Oficiais de Contas, ECLI:EU:C:2013:127 y Sentencia del tribunal de justicia (Sala Segunda) de 14 de marzo de 2019, As. C-724/17, Fenin C-205/03 P o Skanska en https:// eur-lex.europa.eu/legal-content/ES/TXT/HTML/?uri=CELEX:62017CC0724\&from=ES, ECLI:EU:C:2019:204.

${ }^{49}$ Sentencia del Tribunal Supremo de 9 de marzo de 2015, Recurso 294/2013, relativa a la Resolución de la CNC de 14 de abril de 2009 (ECLI : ES:TS:2015:800) (Expediente 639/09, Colegio Farmacéuticos Castilla la Mancha accesible en https:// www.cnmc.es/expedientes/63908).
} 
cedimientos, y no discriminación e igualdad de trato entre los licitadores así como asegurar una eficiente utilización de los fondos públicos mediante la exigencia de la definición previa de las necesidades a satisfacer, la salvaguarda de la libre competencia y la selección de la oferta económicamente más ventajosa ${ }^{50}$.

La CNMC ha manifestado que "las intervenciones de las administraciones públicas en las actividades económicas deben responder a los principios (...) de necesidad, proporcionalidad y no discriminación, sin que puedan introducir restricciones y barreras a la competencia que no estén justificadas en un fallo de mercado o en una razón imperiosa de interés general de las establecidas por el TJUE. Ello es igualmente aplicable al ámbito de la contratación pública" ${ }^{51}$. Recuerda igualmente este órgano administrativo la doctrina asentada en virtud de la cual la administración debe actuar de manera conforme al interés general y debe evitar restricciones y barreras a la competencia que no estén justificadas por su vinculación con razones imperiosas de interés general. También declara que en el ámbito de la contratación pública los principios de competencia efectiva; transparencia y eficiencia en el gasto público; no discriminación e igualdad de trato entre los potenciales candidatos son imperativos para los poderes adjudicadores.

Esta línea de argumentación implica que son precisamente esos principios los que están en la esencia y el sentido originario de la normativa de contratación pública con fundamento "más allá de nuestras fronteras", tal como reconoce el Preámbulo de la Ley de Contratos del Sector Público ${ }^{52}$.

Esta regulación, tiende, estableciendo procedimientos garantistas, a permitir a todos los operadores capacitados intervenir en los procesos de contratación en igualdad de condiciones para conseguir la máxima eficiencia en el gasto público y la máxima calidad en los productos y servicios contratados. No en vano, los objetivos que inspiran la Ley son "lograr una mayor transparencia en la contratación pública" para "conseguir una mejor relación calidad-precio". Por ello la Ley de Contratos establece la obligación de los órganos de contratación de velar por que el diseño de los criterios de adjudicación esté diseñado para alcanzar los citados objetivos. Expresamente se establece que "el sistema legal de contratación pública que se establece en la Ley persigue que la contratación pública "se utilice como instrumento para implementar" una serie de políticas entre las que se encuentra la de competencia.

Cuando la Administración toma la decisión de prestar un servicio por medio de un contrato público, la Ley de contratos del Sector Público establece una serie de obligaciones procedimentales complejas que tienen el objetivo de garantizar los principios de transparencia para "conseguir una mejor relación calidad-precio" por ello debe ser objeto de la normativa de defensa de la competencia ${ }^{53}$.

36. No existe duda de que, cuando la administración actúa como operador económico, está sometida al derecho de la competencia ${ }^{54}$.

Por ello puede concluirse que cuando la actuación de un poder público puede subsumirse dentro del amplio concepto de operador económico, puede ser sujeto activo de una infracción de competencia si llega a acuerdos que cumplan los requisitos del artículo 1 de la LDC o abusa de su posición de dominio en los términos del artículo 2 o competencia desleal con afectación al interés público tal como se tipifica en el artículo $3^{55}$.

${ }^{50}$ Véase la Ley 9/2017, de 8 de noviembre, de Contratos del Sector Público, por la que se transponen al ordenamiento jurídico español las Directivas del Parlamento Europeo y del Consejo 2014/23/UE y 2014/24/UE, de 26 de febrero de 2014, BOE-A-2017-12902.

${ }^{51}$ Resolución de la CNMC de 28 de febrero de 2019 Expte. SAMAD/03/16, ESTACIONAMIENTO REGULADO AYUNTAMIENTO DE MADRID, accesible en la url: https://www.cnmc.es/sites/default/files/2377357_1.pdf.

52 Véase el punto primero del citado Preámbulo cuando establece referencias a la «actividad normativa de instituciones de carácter internacional, como es el caso de la OCDE, de UNCITRAL -en el ámbito de la ONU-, o, especialmente, de la Unión Europea». Ley 9/2017, de 8 de noviembre, de Contratos del Sector Público, por la que se transponen al ordenamiento jurídico español las Directivas del Parlamento Europeo y del Consejo 2014/23/UE y 2014/24/UE, de 26 de febrero de 2014 , BOE-A-2017-12902.

${ }^{53}$ Resolución de 26 de julio de 2018, Expte. S/DC/0565/15 LICITACIONES DEAPLICACIONES INFORMÁTICAS, https:// www.cnmc.es/sites/default/files/2122881 3.pdf y Resolución de 4 de diciembre de 2018, Expte. SAMAD/01/18, CONTRATACIÓN PÚBLICA DE COMUNICACION̄ES MÓVILES, https://www.cnmc.es/sites/default/files/2327928_0.pdf.

${ }^{54}$ Véanse las sentencias del TJUE de 12 de julio de 2012, As. C-138/11Compass-Datenbank, ECLI:EU:C:2012:4499 y de 28 de febrero de 2013, As. C-1/12,Ordem dos Técnicos Oficiais de Contas, ECLI:EU:C:2013:127.

${ }_{55}$ En nuestro ordenamiento, ni los artículos 1, 2 o 3 ni el 61 de la LDC determinan que tan solo las empresas puedan desarrollar 


\section{B) La intervención en una infracción de una entidad que no interviene en el mercado. La figura del facilitador}

37. En un número relevante de casos los poderes públicos inciden en los mercados sin participar directamente en ellos y por tanto debe plantearse si tal participación puede generar responsabilidad desde la perspectiva de la aplicación de la normativa de defensa de la competencia ${ }^{56}$.

38. La jurisprudencia ha asentado la posibilidad de establecer responsabilidad en materia de competencia a aquellas entidades que participen en una conducta en calidad de facilitadores de una infracción de competencia. En virtud de esta jurisprudencia, se considera que debe admitirse en el Derecho Administrativo sancionador la imputación de responsabilidad al margen de la condición de autor de una infracción.

A pesar de que la LDC no recoge expresamente (en contra de lo que sucede en otras legislaciones sectoriales) figuras de participación en una infracción diferentes a la autoría -dado que la del instigador contenida en el artículo 64.2.b) es una agravante que se aplica a los autores de las conductas. posibilidad.

Lo mismo sucede con el Derecho Europeo de Competencia que no recoge expresamente esta

39. A pesar de este silencio normativo, la jurisprudencia europea ha aclarado que existe la posibilidad de determinar responsabilidad en una infracción de competencia sin que exista título de autoría.

La Sentencia Treuhand I del entonces Tribunal de Primera Instancia de la Unión Europea estableció que cualquier operador -persona física o jurídica- independientemente de que participe o no en el mercado afectado por la infracción debe ser considerado facilitador de la conducta y por tanto responsable de la misma en el caso de que contribuya de manera decisiva y activa a la realización de la práctica anticompetitiva ${ }^{57}$.

En un asunto similar -el denominado Treuhand II- se analiza si resulta exigible o no que el facilitador del cártel opere de manera activa como empresa, sea en el mercado afectado por la conducta o en otro conexo. En el citado supuesto se dictó una sentencia por el ahora Tribunal General en la que se dispone que no cabe establecer esta exigencia ${ }^{58}$. Si bien esta sentencia fue recurrida en casación, el Tribunal de Justicia desestimó el recurso formulado por la empresa confirmando plenamente la anterior resolución ${ }^{59}$.

40. La Sala Tercera del Tribunal Supremo español fue más allá en la citada construcción cuando confirmó no solo la posible aplicación de la figura del facilitador en el ordenamiento español, sino que la misma pudiera ser ejercida por una administración.

En su Sentencia de 18 de julio de 2016 el TS confirma la resolución de la CNC en que se consideró que la Consejería de Agricultura de la Junta de Andalucía era responsable como facilitadora de un cártel llevado a cabo por un grupo de productores de vino de Jerez, conocido y auspiciado por la Junta.

La actuación administrativa se sanciona, teniendo en cuenta el papel activo de la Consejería en las reuniones, que iba más allá de sus funciones propias ${ }^{60}$. De hecho, el Tribunal Supremo considera

\footnotetext{
las conductas colusorias. El hecho de que el artículo 63 se refiera a los agentes económicos y empresas se debe a que el precepto determina la cuantía máxima de las sanciones referida a un porcentaje de su volumen de negocios, "criterio que, ciertamente, no resulta adecuado cuando la conducta se reprocha a una administración o entidad jurídico pública; lo que no excluye, sin embargo, que ésta pueda haber incurrido en una conducta prohibida de las definidas en el artículo 1 de la propia Ley" (STS de 2016).

${ }^{56}$ E.Linde Paniagua, "¿Libre competencia e interés general en la Ley de contratos del sector público?", en Revista de Derecho de la Unión Europea. $\mathrm{n}^{\circ} 30 . \mathrm{n}^{\circ} 31$. Reflexiones en torno a la competencia en la Unión Europea. Construyendo un estándar europeo de protección de los derechos humanos, Ediciones Académicas S.A., Madrid, 2016, págs. 203 a 221.

${ }^{57}$ Sentencia del Tribunal de Primera Instancia de 8 de julio de 2008 asunto Treuhand I, T-99/04, (ECLI:EU:T:2008:256).

${ }^{58}$ Sentencia del Tribunal General de 6 de febrero de 2014, As T-27/10, (ECLI:EU:T:2014:59).

59 Sentencia del Tribunal de Justicia de 22 de octubre de 2015, As. C-194/14 P, (ECLI:EU:C:2015:717).

${ }^{60}$ Sentencia del Tribunal Supremo de 18 de julio de 2016, Recurso 2946/2013, (ECLI: ES:TS:2016:3525), dictada respecto de la Resolución de 6 de octubre de 2011 de la CNC en el expediente S/167/09 productores de uva y vino de Jerez accesible en https://www.cnmc.es/expedientes/s016709.
} 
que la participación en la actividad económica y en la infracción del artículo 1 LDC no excluye las categorías tradicionales del derecho penal como son el instigador o inductor, el cooperador necesario, etc.

El Tribunal Supremo afirmó que la administración debía reputarse responsable del cártel sancionado, a pesar de que no actuaba como operador económico, teniendo en cuenta que su papel fue activo y que el mismo iba más allá de sus funciones propias. Por lo tanto la mera aptitud de la conducta realizada para causar "un resultado económicamente dañoso o restrictivo de la competencia en el mercado" resulta suficiente para considerar a la administración responsable de la infracción ${ }^{61}$.

Debe recordarse en este sentido, la doctrina apuntada en la citada Sentencia de referencia en virtud de la cual no puede pretenderse "sustraer del ámbito de aplicación del Derecho de la Competencia cualquier conducta que se realice al amparo de una norma sino, únicamente, aquellas conductas a las que una Ley autorice con la específica finalidad, expresa o implícita- de excluirlas del ámbito de aplicación de las prohibiciones".

41. Muy recientemente el Tribunal Supremo ha vuelto a manifestarse en la misma línea en el recurso planteado por TEXPOL contra la resolución AIO de la $\mathrm{CNMC}^{62}$.

La cuestión planteada en el recurso que presenta interés casacional objetivo para la formación de la jurisprudencia consiste en interpretar los artículos 1 y 61.1 de la LDC, en relación con el artículo 1 del TFUE y la jurisprudencia aplicable, a fin de determinar el grado de responsabilidad (o, en su caso, su exclusión) de aquellas empresas que tienen conocimiento de la dinámica de una práctica colusoria o la facilitan, pero no compiten en el mercado afectado.

El TS afirma que "constituye infracción en materia de competencia la conducta de una empresa que participa activamente en los actos de constitución de un cártel aunque dicha empresa no comercialice productos en el mercado principal de referencia pero si lo haga en un mercado conexo del de referencia, y cuya intervención activa en las prácticas colusorias debe ser corregida mediante la imposición de la correspondiente sanción, debiendo interpretarse en dicho sentido los artículos 1 y 61.1 LDC en relación con el artículo 101 TFUE”.

El TS llega a dicha conclusión al considerar que "No hay nada en la redacción del artículo 101 TFUE, apartado 1, que indique que la prohibición que establece se refiera únicamente a las partes en los acuerdos o prácticas concertadas que operen en los mercados afectados por éstos. La intervención de una empresa en los actos constitutivos de un cártel, aun cuando no comercialice productos en el mercado principal de referencia pero sí en un mercado vinculado o conectado al mismo- puede considerarse una conducta típica con arreglo a lo dispuesto en el artículo 61.1 LDC en relación con el artículo 1 del mismo texto legal y con el artículo 101 TFUE (...) Lo contrario permitiría sentar un criterio de impunidad en relación con aquellas conductas colusorias de empresas vinculadas que, sin embargo, no comercializan productos en el mercado principal de referencia".

Afirma el TS que "lo mismo cabe decir, no solo si el partícipe activo no forma parte del mercado de referencia, por su condición de participe en un mercado conexo como sucede en este caso, sino también, por su condición de Autoridad administrativa".

42. Todo cuanto antecede permite concluir que la condición jurídica del infractor y el hecho de que actúe o no como operador económico no son factores determinantes para apreciar la existencia de una infracción.

\footnotetext{
${ }^{61}$ Resultan de especial interés por la aproximación ofrecida por la Autoridad Suiza de Competencia considerando la existencia de abuso de posición de dominio de los poderes adjudicadores cuando realizan inadecuadamente contratos públicos las resoluciones DPC 2007/4, p. 517, Beschaffung von Leichten Transport- und Schulungshelikoptern durch armasuisse y DPC 2008/2, p. 356-357, Verbesserung des Rechtsschutzes bei Beschaffungen durch armasuisse.

${ }^{62}$ Mediante Sentencia del Tribunal Supremo (Sala de lo Contencioso-Administrativo, Sección Tercera) de 21 de mayo de 2020, se ESTIMA el recurso de casación número 7880/2018, interpuesto por la CNMC contra la SAN de 29 de mayo de 2018 (rec. 369/2016), que se anula y se DESESTIMA el recurso contencioso administrativo interpuesto por la entidad Textil Planas Oliveras, S.A. (TEXPOL) contra la RCNMC de 26 de mayo de 2016 (expediente S/DC/0504/14 AIO), confirmando la infracción declarada por la CNMC y la multa impuesta.
} 
Lo relevante es la incidencia real de la conducta de la entidad en el mercado o la aptitud de la acción pública para impulsar, generar o reforzar los efectos restrictivos de la conducta en la que participa.

El Tribunal de Justicia de la Unión Europea ha confirmado la posibilidad de declarar la responsabilidad de una entidad como facilitador en una infracción de competencia, aunque no opere en el mercado afectado ni en mercados conexos, siempre que contribuya de manera decisiva y activa a la realización de una conducta anticompetitiva y que el Tribunal Supremo español ha precisado que nada obsta a que sea un poder público quien actúe en tal condición.

El hecho de que las citadas Sentencias se refieran a conductas multilaterales (artículo 1 LDC) en nada obsta para que la citada doctrina pueda aplicarse a conductas de la Administración tipificadas como abuso de posición de dominio (artículo 2 LDC) o competencia desleal con afectación al interés general (artículo 3 LDC) si se cumplen las exigencias citadas ya que la doctrina definida se refiere con carácter general a las infracciones de competencia y al nivel de autoría del sujeto activo sin que ninguna de las valoraciones impida la aplicación a cualquier tipo infractor.

\section{C) Un posible análisis de la potestad normativa desde la perspectiva de defensa de la competencia}

43. Desde una perspectiva de Defensa de la Competencia, a Ley española establece, en su artículo 4, que tan solo algunas conductas están exentas de fiscalización por parte de las autoridades de competencia y que tales exenciones deben estar recogidas normas con rango de Ley.

El precepto establece expresamente que las prohibiciones contenidas en la LDC se aplican a restricciones que se deriven del ejercicio de "otras potestades administrativas o sean causadas por la actuación de los poderes públicos o las empresas públicas sin dicho amparo legal". El precepto identifica, de manera evidente, que tales afirmaciones se realizan "sin prejuicio de" las disposiciones de la Unión Europea.

Del mismo se deducen varias conclusiones.

44. En primer lugar que en el ordenamiento jurídico español las autoridades de competencia pueden evaluar bajo la perspectiva de la Defensa (que es la abordada en la Ley de Defensa de la Competencia) todas las actuaciones de los poderes públicos independientemente de su rango normativo, siempre que éstas puedan considerarse contrarias a la normativa de la Unión Europea, dados los principios de primacía y efecto directo que tienen las normas europeas ${ }^{63}$.

38. "Tal como ha declarado el Tribunal de Justicia en reiteradas ocasiones, el mencionado deber de excluir la aplicación de una normativa nacional contraria al Derecho de la Unión no solamente incumbe a los jueces y tribunales nacionales, sino también a todos los órganos del Estado - incluidas las autoridades administrativas - encargados de aplicar, en el marco de sus respectivas competencias, el Derecho de la Unión (véanse, en este sentido, las sentencias de 22 de junio de 1989, Costanzo, 103/88, EU:C:1989:256, apartado 31; de 9 de septiembre de 2003, CIF, C-198/01, EU:C:2003:430, apartado 49; de 12 de enero de 2010, Petersen, C-341/08, EU:C:2010:4, apartado 80, y de 14 de septiembre de 2017, The Trustees of the BT Pension Scheme, C-628/15, EU:C:2017:687, apartado 54)".

39. De lo anterior se deduce que el principio de primacía del Derecho de la Unión no impone la obligación de garantizar la plena eficacia de las normas de la Unión únicamente a los órganos judiciales, sino también a todos los demás órganos e instituciones del Estado miembro.

De cuanto antecede puede concluirse la obligación del poder público de respeto a la normativa de la UE en su toma de decisión. Del artículo 129 de la LPA la obligación de respetar los principios de buena regulación tal como los hemos desarrollado.

La doctrina del facilitador implica que no es necesario operar en el mercado para ser facilitador de una conducta contraria a la competencia y que puede serlo un poder público.

${ }^{63}$ Véase la Sentencia del Tribunal de Justicia de 4 de diciembre de 2018 As. C378/17, Minister for Justice and Equality, Commissioner of An Garda Síochána y Workplace Relations Commission, ECLI:EU:C:2018:979. 
La confluencia de todos esos elementos nos lleva a no excluir la posibilidad de que un poder público fuera considerado responsable como facilitador de una conducta contraria a la competencia cuando crea una norma que favorece una conducta contraria a la competencia en contravención de tales exigencias.

45. Dentro del ordenamiento jurídico español, siempre que no exista afectación a la normativa europea, el legislador ha decidido que corresponde a los parlamentos correspondientes la ponderación entre los diferentes intereses que pueden entrar en conflicto con el de competencia.

De este modo, en el caso de que el legislador considere que existe un valor superior a la competencia digno de protección, debe introducir las posibles barreras a la competencia en normas con rango de Ley.

Cuando esto suceda las autoridades de competencia carecerán de capacidad de analizar la situación desde una perspectiva de defensa de la competencia.

Sin embargo si existen normativas de rango inferior a la Ley contraria a la competencia y que facilite la existencia de barreras de entrada a ciertos operadores o discriminaciones no necesarias ni proporcionales a una RIGG también podrían analizarse desde la perspectiva de competencia dependiendo de los casos.

\section{Sobre la relación entre la Defensa de la Competencia y otras reacciones posibles del ordena- miento}

46. Hemos referido diversas posibilidades de reacción de las autoridades de competencia ante las restricciones a la competencia generadas por poderes públicos.

El análisis de su relación con otras posibles reacciones del ordenamiento jurídico y la existente entre las dos funciones entre sí parece procedente, dado que las autoridades de competencia están afectadas por el principio de eficacia de la actuación administrativa contenido en la Constitución. Además, en la medida en que las autoridades de competencia nacionales tienen la obligación de aplicar la normativa europea de competencia, debe garantizar su efecto útil lo que tiene una relevante trascendencia.

\section{Relación entre el Derecho de la competencia y otras áreas del ordenamiento}

47. Subyace en la actuación de algunas autoridades de competencia la concepción de que su capacidad de acción debería decaer si existen otras normativas que resulten de aplicación para valorar la legalidad de los actos llevados a cabo por las administraciones ${ }^{64}$.

Tal situación de confluencia puede darse cuando conductas que pueden subsumirse en tipos de la normativa de competencia están también abordados por otras normas como por ejemplo, la normativa penal, la de contratos del sector público, la de concesiones u otras vinculadas; la de protección de los consumidores; la de protección de los trabajadores; la fiscal; la penal, o las normativas sectoriales entre otras.

Esta valoración no puede considerarse al menos en todo caso correcta, tal como desarrollamos a continuación.

48. El hecho de que existan normativas (ordinariamente de Derecho Público) que sancionen, prohíban o al menos regulen de maneras alternativas los hechos que pueden ser enjuiciados por la auto-

${ }^{64}$ Véanse las mencionadas Resolución de la CNMC de 28 de febrero de 2019 Expte. SAMAD/03/16, ESTACIONAMIENTO REGULADO AYUNTAMIENTO DE MADRID, en https://www.cnmc.es/sites/default/files/2377357_1.pdf; Resolución de la CNMC de 26 de julio de 2018, Expte. S/DC/0565/15 LICITACIONES DE APLICACIONES INFORMÁTICAS, en https:// www.cnmc.es/expedientes/sdc056515. Del mismo modo la resolución dictada en el Expte. SAMAD/08/18, UNIFORMES DE COLEGIO o Resolución del Consejo de la ADCA en el Expte. S/02/2010 - Distribución de Uniformes Escolares, de 23 de febrero de 2010. 
ridad de competencia no debe obstar a la actuación de ésta siempre que la conducta analizada sea subsumible en los tipos de la Ley de Defensa de la Competencia con las interpretaciones jurisprudenciales que la acompañan.

Esta afirmación es más clara en el caso del ordenamiento jurídico español, si existen denuncias, dado que la autoridad de competencia no tiene en este momento la posibilidad de priorizar asuntos y por tanto tiene la obligación de resolver las denuncias presentadas ${ }^{65}$.

De otro modo, se estaría reconociendo una jerarquía de reacciones del ordenamiento que, en el caso de que exista diferencia de bienes jurídicos protegidos, tan solo encuentra su justificación en la prejudicialidad penal. La misma está regulada en la LDC (artículo 47) de una forma restrictiva ya que se establece que tan solo la existencia de una "cuestión prejudicial penal de la que no pueda prescindirse para dictar la resolución o que condicione directamente el contenido de ésta determinará la suspensión del procedimiento mientras aquélla no sea resuelta por los órganos penales a quien corresponda". Tal situación no se verifica de manera ordinaria. De hecho podría decirse que resulta extraordinariamente infrecuente que no pueda prescindirse de la instrucción penal para dictar una resolución sancionadora en materia de competencia ${ }^{66}$.

Existen muy escasos supuestos en que un expediente administrativo sancionador en materia de competencia se suspenda por prejudicialidad penal. De hecho, en algunos de ellos tal situación parece que podría estar justificada por una falta de voluntad de analizar las implicaciones de competencia cuando existen otras que pueden considerarse más graves y que por lo tanto, de ser sancionadas cubrirían las funciones de sanción y disuasión de manera suficiente.

Esta valoración desconoce sin embargo las enormes posibilidades de que la conducta no cumpla las exigencias de prueba o gravedad como para merecer sanción penal sin que tras el enjuiciamiento penal sea muy posiblemente reiniciar la tramitación del procedimiento administrativo por prescripción o falta de oportunidad. Ello supone que la conducta quede impune también desde la perspectiva de competencia.

Por ello la interpretación del artículo 47 de la LDC debería realizarse de manera literal y limitarse a los supuestos estrictamente recogidos en el mismo sin que se emplee una posible responsabilidad penal relacionada con los hechos analizados por la autoridad de competencia para archivar el procedimiento administrativo con riesgo de dejar impune una conducta tipificada.

49. Cuando la confluencia de posibles infracciones lo es con alguna otra rama del ordenamiento, ni siquiera la exigencia de prejudicialidad existe por lo que en caso de diferentes intereses jurídicamente protegidos no existe problema en la declaración de varias infracciones del ordenamiento y nada obsta, obviamente, a la sanción desde una perspectiva de competencia.

Incluso puede concluirse que en algunos casos, si se ha declarado la existencia de una infracción de otras normas jurídicas (sectoriales, de contratación, laborales, fiscales...) que genere competencia desleal con infracción del interés general, se facilitaría sensiblemente la incoación y consiguiente sanción por la autoridad de competencia ante una infracción del artículo 3 de la LDC.

50. Finalmente, en el caso de que existiese una confluencia de tipos infractores con identidad de intereses jurídicamente protegidos entre la normativa de competencia y otra rama del ordenamiento, po-

\footnotetext{
${ }^{65}$ La normativa española será modificada para introducir priorización de asuntos debido a la normativa europea con los riesgos y ventajas que tal posibilidad plantea. Directiva (UE) 2019/1 del Parlamento Europeo y del consejo de 11 de diciembre de 2018 encaminada a dotar a las autoridades de competencia de los Estados miembros de medios para aplicar más eficazmente las normas sobre competencia y garantizar el correcto funcionamiento del mercado interior. DOUE 11/3 de 14 de enero de 2019.

${ }^{66}$ Véanse, por ejemplo, asuntos como la Resolución del Consejo de la CNC de 26 de septiembre de 2013 Expte. S/314/10, Puerto de Valencia; Resolución del Consejo de la CNC en el Expte. S/0293/10 - TRANSCONT. Puerto de Barcelona, de 10 de enero de 2013; STS 3631/2018 - ECLI: ES:TS:2018:3631; las Sentencias del Tribunal Supremo referidas a la resolución de la Autoridad Vasca de la Competencia sobre el transporte horizontal en el Puerto de Bilbao, de 10 de octubre de $2018 \mathrm{~N}^{\circ}$ de Recurso: 4387/2017; o las dictadas por el Tribunal Superior de Justicia del País Vasco a raíz de la resolución de la Autoridad Vasca de la Competencia en el asunto Pinosolo STSJ de 15 de febrero de 2016, ECLI:ES:TSJPV:2016:255.
} 
drían aplicarse de manera analógica las teorías del concurso del derecho penal y plantearse la posibilidad de declarar o no, dependiendo de los casos dos infracciones o imponer dos sanciones (siempre teniendo en cuenta la primera al decidir sobre la segunda).

En cualquier caso lo que no parece tener base jurídica ninguna es defender el archivo o no incoación de un expediente por esta razón, carente de base jurídica en el ordenamiento español.

\section{La relación entre las vías de promoción y defensa de la competencia}

51. Tal como hemos indicado previamente, existen definiciones negativas de la promoción de la competencia que la conceptúan por comparación con la defensa y consideran que constituye promoción toda aquella actividad de salvaguarda de la competencia que no se enmarca en los tipos infractores de la defensa.

De tal definición podría derivarse que existe una relación excluyente entre ambas funciones. Sin embargo tal conclusión resulta errónea porque promoción y defensa son interdependientes en muchos aspectos. Tales afirmaciones se recogen por los trabajos publicados por la $\mathrm{OCDE}^{67}$. La misma organización subraya que las tareas de defensa y promoción no son ni pueden ser excluyentes dado que su interacción genera beneficios cruzados que no pueden ser desdeñados. La promoción de la competencia sirve sin duda a evitar conductas contrarias a la competencia y a detectarlas. La credibilidad de una autoridad de Competencia no puede medirse solo en conductas de promoción sino que requiere, obvia y especialmente, de la defensa ${ }^{68}$. La interacción bidireccional se ha puesto de manifiesto por las más importantes autoridades de competencia del mundo por las ventajas para el interés general que pueden obtenerse del trabajo coordinado en general y en casos concretos ${ }^{69}$.

\section{A. La solución reciente de las autoridades de competencia en España}

52. La CNMC ha realizado determinados archivos recientemente de los que podría deducirse que existe una relación excluyente entre las funciones de promoción y defensa de la competencia, al menos en lo tocante a la relación con las actuaciones de los poderes públicos ${ }^{70}$.

\footnotetext{
${ }^{67} \mathrm{DAF} / \mathrm{COMP} / \mathrm{LACF}(2010) 4$, citado.

${ }^{68}$ Transcribo, por su pertinencia en relación a la argumentación realizada las valoraciones de la OCDE "Such a definition suggests that advocacy and enforcement are mutually exclusive, but they are not. In many ways they are interdependent. Thus, as noted above, effective competition advocacy in the privatisation and regulatory reform processes can favourably impact enforcement by creating competitive markets, in which future abuses of dominance and collusion are less likely to occur. Success in building a competition culture has obvious benefits for enforcement: businesses will more readily comply voluntarily with the competition law; businesses and the public will more willingly co-operate with enforcement actions, by providing evidence and the like; and policy makers will more enthusiastically support the mission of the competition agency, in particular by giving more resources to it.

Perhaps less well appreciated is how competition law enforcement can affect competition advocacy. Noted above is the importance of the agency's credibility and reputation to successful competition advocacy efforts. Such credibility cannot be gained through advocacy alone; it must be enhanced by success in enforcing the competition law. It is imperative that the agency select and successfully prosecute cases that are widely viewed as beneficial to consumers, whether they involve destructive cartels, high profile, anticompetitive mergers or abusive conduct by notorious dominant firms. In the end, a competition agency's reputation will be built largely upon its record in enforcing the competition law, and this reputation will significantly affect its influence as an advocate in other forums".

${ }^{69}$ La Office of Fair Trading (OFT) en el Reino Unido realizó en 2009 una acción en que vinculó defensa (imposición de una sanción a 103 empresas de construcción por un caso de bid rigging) OFT press release of 22 September 2009, Construction firms fined for illegal bid-rigging, en http://www.oft.gov.uk/news-and-updates/press/2009/114-09.

Simultáneamente realizó un informe dirigido a los poderes adjudicadores públicos y privados recomendando que no impusieran a las empresas responsables la prohibición de contratar y dando orientaciones para que se redactaran los pliegos de forma que pudieran evitarse en la medida de lo posible casos semejantes en el futuro. En http://www.oft.gov.uk/shared_oft/ business_leaflets/general/CE4327-04_Decision_public_1.pdf.

70
} 
53. Tomemos como ejemplo la resolución dictada en el caso Easypark ${ }^{71}$. Los hechos de la resolución parten de la existencia de un contrato de concesión que "tiene por objeto la gestión, regulación y control del estacionamiento de vehículos en determinadas zonas y plazas de la vía pública" en una ciudad española para su adjudicación a través de un procedimiento abierto dividido en 4 lotes que se adjudican a sendas UTE.

El pliego de prescripciones técnicas del contrato indica que los parquímetros tendrán habilitados una serie de sistemas de pago del servicio por el usuario, sin perjuicio de que puedan ser ampliados a través de cualquier otro medio o dispositivo que en el futuro la tecnología permita. Entre ellos se encuentra el pago a través de dispositivos electrónicos móviles. El pliego exige a las entidades adjudicatarias la creación de una plataforma integral que permita los pagos mediante aplicaciones móviles en todo el territorio afectado por el contrato. Las adjudicatarias definieron que el pago se realizase por medio de tres sistemas de pago, propiedad de tres operadores vinculados con ellas mismas que se diseñaron como interoperables para ser compatibles entre sí permitiendo en pago en todo el territorio con cualquiera de ellas.

Sin embargo, cuando un operador diferente solicitó el acceso a la plataforma para permitir el pago con una aplicación diferente, la administración manifestó que el concesionario podía permitir el pago con las aplicaciones que considerara pertinente y además no facilitó el acceso alegando que el mismo se rige por el Pliego de Prescripciones técnicas.

Posteriormente, como resultado de una Terminación Convencional iniciada por el servicio de instrucción, el Ayuntamiento dictó unas instrucciones que establecían la obligación a las concesionarias de garantizar el acceso a la plataforma a cualquier empresa interesada en participar en el servicio, sin exigir expresamente estableciendo los cauces eficientes para garantizarlo un acceso no discriminatorio a la misma (tal como sería exigible por aplicación de la LDC tanto para el propio ayuntamiento como para las adjudicatarias).

La CNMC manifiesta en su resolución que "el diseño de la propia concesión debe evitar la creación de barreras a la competencia innecesarias o desproporcionadas con los objetivos de la concesión, o la extensión de la posición dominante a actividades o mercados conexos que puedan funcionar en condiciones competitivas de mercado" y que "la inclusión del servicio de pago del estacionamiento regulado por medio de Apps como una de las prestaciones del Contrato podría dar lugar a una restricción injustificada de la competencia si no se garantiza el acceso a operadores potenciales en condiciones de igualdad y no discriminación".

Del mismo modo afirma la Sala que "en aquellas situaciones en las que un control público sobre la entrada al mercado se justifica con arreglo a razones de calidad o seguridad, la elección de un mecanismo de cierre absoluto como la concesión a uno o varios operadores en exclusiva no resultaría congruente con el principio de mínima distorsión, ya que tal régimen podría sustituirse por un sistema de autorización administrativa. Tal sería el caso del mercado de servicios de pago del estacionamiento regulado mediante App, de modo que todas aquellas entidades capacitadas para ofrecer el servicio en condiciones que permitan la recepción de las tasas correspondientes por el Ayuntamiento, bajo determinados parámetros de seguridad, deberían poder entrar en el mercado, si así lo consideran, con el mero cumplimiento de determinados requisitos cuya imposición sólo corresponde a la Administración".

A pesar de esas afirmaciones, la conclusión a que llega la Sala, de manera mayoritaria, es que el expediente debe ser archivado. Para ello se basa en los siguientes argumentos:

- que "las posibles barreras a la competencia derivadas del diseño y contenido del contrato de concesión de la gestión del servicio de estacionamiento regulado (posible reserva de un mercado conexo al de la concesión) deben abordarse desde otra aproximación" ${ }^{72}$.

\footnotetext{
${ }^{71}$ Véanse nuevamente las mencionadas Resolución de la CNMC de 28 de febrero de 2019 Expte. SAMAD/03/16, ESTACIONAMIENTO REGULADO AYUNTAMIENTO DE MADRID, en https:/www.cnmc.es/sites/default/files/2377357_1. pdf; Resolución de la CNMC de 26 de julio de 2018, Expte. S/DC/0565/15 LICITACIONES DE APLICACIONES INFORMÁTICAS, en https://www.cnmc.es/expedientes/ sdc056515. Del mismo modo la resolución dictada en el Expte. SAMAD/08/18, UNIFORMES DE COLEGIO o Resolución del Consejo de la ADCA en el Expte. S/02/2010 - Distribución de Uniformes Escolares, de 23 de febrero de 2010.

72 Véase la resolución SAMAD/03/16, citada.
} 
- que el Ayuntamiento "es, en este caso, de acuerdo con la normativa vigente, un "órgano de contratación” " "poder adjudicador" de una concesión de ámbito local para la gestión del estacionamiento regulado" y por tanto no actúa "como operador económico sino como administración". De este modo determina que "las concesiones objeto del expediente no pueden constituir una actuación anticompetitiva o abusiva, debiendo, en su caso, ser impugnadas conforme a otros criterios de legalidad cuyo examen corresponde a la Jurisdicción Contencioso-Administrativa".

- que "al no participar la administración en la prestación directa de estos servicios, ni de ningún otro relacionado o conexo, no es posible poder apreciar una posición de dominio del mismo en el mercado de servicios de pago del estacionamiento regulado mediante App".

Es decir, el expediente se archiva porque la administración no puede considerarse operador económico y por considerar que las limitaciones a la competencia denunciadas y acreditadas deberían haberse abordado desde la perspectiva de la promoción de la competencia y no desde la perspectiva de defensa.

54. Esta visión de la situación no es compartida por todas las autoridades de competencia españolas. Así lo han mantenido diversas resoluciones administrativas confirmadas en algunos casos por los tribunales ${ }^{73}$.

55. Numerosas resoluciones de autoridades de competencia en España han considerado a diversas entidades públicas responsables de infracciones a la normativa de competencia empleando la defensa por considerarla más eficaz que la vía de la impugnación para garantizar un adecuado estándar de protección del interés general.

El Tribunal de Defensa de la Competencia declaró en el año 2000 al Ayuntamiento de Benasque responsable de una conducta de abuso de posición de dominio y competencia desleal. La administración actuaba, indudablemente, en calidad de operador económico ${ }^{74}$.

En el mismo año la misma instancia sancionó un acuerdo para contingentar el número de licencias de taxi que podían trabajar a doble turno a doble turno en Barcelona. Se declaró responsables al Institut Metropolitano del Taxi, dependiente del Ayuntamiento de Barcelona como promotor y como firmantes a una serie de sindicatos de taxistas ${ }^{75}$.

La Comisión Nacional de la Competencia declaró en el año 2008 al Ayuntamiento de Peralta responsable de una infracción por llevar a cabo un acuerdo con una asociación de feriantes que impedía la entrada en las fiestas de ciertas entidades. La resolución entiende que el convenio se suscribe para evitar la competencia entre las industrias feriales y similares durante las fiestas locales del municipio y durante los ejercicios 2005, 2006 y $2007^{76}$. A la entidad firmante se le sanciona por abuso de posición de dominio.

En 2013 la CNC sancionó a un grupo de entidades junto con la administración autonómica y la autoridad portuaria por la realización de un acuerdo de cierre de mercado de transportistas en el puerto ${ }^{77}$

En 2014 la Autoridad Vasca de la Competencia terminó convencionalmente un expediente contra tres Colegios de Farmacéuticos, las administraciones provinciales vascas y el Gobierno Vasco, por la suscripción de un acuerdo en virtud del cual determinadas oficinas de farmacia prestaban los medicamentos con un determinado descuento a las residencias de ancianos a cambio de que el Gobierno no

${ }^{73}$ Véase la Resolución de la Autoridad Vasca de la Competencia, Expte. 07/2011, Contrato Telefónico Ayuntamiento de Bilbao, de 7 de septiembre de 2012, confirmada por Sentencia del Tribunal Supremo Sala Tercera Recurso 940/2012 de 23 de mayo de 2017 y Resolución del Consejo de Defensa de la competencia de Andalucía S/01/2018, José Manuel Pascual PasCUAL de 2 de marzo de 2018, en http:/www.juntadeandalucia.es/defensacompetencia/sites/all/themes/competencia/files/pdfs/ Resoluci\%C3\%B3n\%20S-01-2018_1.pdf

74 Véase la Resolución del Tribunal de Defensa de la Competencia de 25 de octubre de 2000, Expte. R 393/98, Eléctrica de Eriste, en https://www.cnmc.es/expedientes/r-33698.

${ }^{75}$ Resolución del Tribunal de Defensa de la Competencia de 29 de marzo de 2000, Expte. 452/99, Taxis Barcelona, en https://www.cnmc.es/expedientes/45299.

${ }^{76}$ Resolución de la CNC de 7 de mayo de 2008 Expte. 632/07, Feriantes Ayuntamiento de Peralta en https://www.cnmc. es/sites/default/files/35443_7.pdf.

${ }^{77}$ Resolución del Consejo de la CNC de 26 de septiembre de 2013 Expte. S/314/10, Puerto de Valencia. 
realizara un desarrollo reglamentario que permitía la distribución de medicamentos a entidades diferentes de las oficinas de farmacia ${ }^{78}$.

También en 2014 la autoridad andaluza de competencia sanciona al Ayuntamiento de Granada y a dos colegios profesionales por realizar un acuerdo en virtud del cual se cierra el mercado de las inspecciones técnicas de edificios a determinados profesionales ${ }^{79}$.

La ACCO sancionó al Ayuntamiento de Hospitalet de Llobregat por realizar una recomendación referida al traslado de cadáveres ${ }^{80}$.

La Resolución de la Autoridad Catalana de la Competencia, en el Expediente Institut Municipal de Parcs $i$ Jardins de Barcelona, impuso una sanción por abuso de posición de dominio al ente dependiente del Ayuntamiento de Barcelona por licitar una exclusiva de suministro de determinadas marcas de productos de helados que posteriormente eran impuestas a los chiringuitos adjudicatarios de las licencias de ocupación en las playas de Barcelona. En el pliego de cláusulas administrativas particulares del contrato de exclusiva de marca de productos a distribuir en los quioscos de las playas de Barcelona se fija un canon mínimo anual de 425.000 euros. La resolución fue recurrida por la CNMC por considerar que la conducta no podía ser objeto de defensa de la competencia sino tan solo de actos de promoción pero fue confirmada por el Tribunal Superior de Justicia de Cataluña ${ }^{81}$.

La AVC llevó a cabo en 2015 un expediente contra una administración provincial y un grupo de ayuntamientos porque habían suscrito un acuerdo en virtud del cual el medio propio de la administración provincial prestaría servicios de diseño de proyectos a los ayuntamientos, cerrando el mercado al sector privado y en condiciones sensiblemente menos eficientes que las ofrecidas por éste ${ }^{82}$.

En 2017 la misma AVC resolvió un expediente de bid rigging en el sector del transporte por carretera de Gipuzkoa que se había incoado contra la administración, una empresa pública dependiente del Gobierno Vasco y el funcionario encargado de la contratación Transporte de Gipuzkoa. A pesar del contenido de la Propuesta de Resolución, el Consejo consideró no acreditada la infracción para todos los entes o personas vinculados el poder público ${ }^{83}$.

El citado asunto resulta especialmente interesante ya que las adjudicaciones de las licitaciones cuya alteración se acreditó en el expediente de defensa fueron impugnadas al considerar la autoridad de competencia que el diseño de los pliegos y la valoración de las ofertas no era acorde a derecho y buscaba que las empresas incumbentes fueran las adjudicatarias de los nuevos concursos. Sin embargo, las impugnaciones fueron desestimadas al considerar los tribunales que se debían haber impugnado los pliegos en lugar de las adjudicaciones, cuestión que no fue posible, dado que la conducta se conoció transcurridos los plazos procesales para esta posibilidad ${ }^{84}$.

${ }^{78}$ Resolución de la AVC de 4 septiembre 2014, Expte. 10/2012, Servicios Farmacéuticos Residencias 2, en http://www.competencia.euskadi.eus/contenidos/informacion/resoluciones/es_resoluci/Resoluci\%C3\%B3n\%20Servicios\%20 Farmac\%C3\%A9uticos\%20Residencias\%202_web.pdf.

${ }^{79}$ Resolución del Consejo de Andalucía 18 de junio de 2014S/12/2014 Inspección de edificios Granada en Resolución del Consejo de Andalucía 18 de junio de 2014S/12/2014 Inspección de edificios Granada, en http://www.juntadeandalucia.es/defensacompetencia/sites/all/themes/competencia/files/pdfs/S\%2012\%202014.pdf.

${ }^{80}$ Resolución de la ACCO de 25 de noviembre de 2014, Exp. n. ${ }^{\circ}$ 40/2011, Servicios Funerarios del Llobregat en http://acco. gencat.cat/web/.content/80_acco/documents/arxius/actuacions/Resolucio-exp-40-2011-esp.pdf.

${ }^{81}$ Resolución de la l'Autoritat Catalana de la Competència de 14 de julio de 2014 Expediente Institut Municipal de Parcs i Jardins de Barcelona recurrida por la CNMC y confirmada por el Tribubunal Superior de Justicia de Cataluña en Sentencia de 1 de junio de 2017 Recurso 462/2014.

${ }_{82}$ Resolución de la Autoridad Vasca de la Competencia de 11 de noviembre de 2015, Expte. 7/2013, OBRAS PÚBLICAS ÁLAVA (Arabako lanak), en https://www.competencia.euskadi.eus/contenidos/informacion/resoluciones/es_resoluci/adjuntos/RESOLUCION\%20arabako\%20lanak\%20definitiva\%20 1 in \%20firmas.pdf.

${ }^{83}$ Resolución de la Autoridad Vasca de la Competencia de 27 de diciembre de 2017, Transporte de viajeros de Gipuzkoa, Proyecto $\mathrm{n}^{\circ}$ 130-SAN-2016, en https://www.competencia.euskadi.eus/contenidos/informacion/resoluciones/es_resoluci/adjuntos/130_RESOLUCION_TRANSPORTE_GIPUZKOA_web_es.pdf.

${ }^{84}$ Véanse las Sentencias del Tribunal Superior de Justicia del País Vasco. Sala de lo Contencioso de 6 de julio de 2016, Rec. 2285/2016 - ECLI: ES:TSJPV:2016:2285; Sentencia del Tribunal Superior de Justicia del País Vasco, Sala de lo Contencioso de 14 de diciembre de 2016, Rec. 4211/2016 - ECLI: ES:TSJPV:2016:4211; Sentencia del Tribunal Superior de Justicia del País Vasco, Sala de lo Contencioso de 20 de diciembre de 2016, Rec 444/2015, ECLI: ES:TSJPV:2016:4210; Sentencia del Tribunal Superior de Justicia del País Vasco,. Sala de lo Contencioso de 2 de marzo de 2017, Rec. 443/2015, ECLI: ES:TSJPV:2017:1191. 
La consecuencia de toda la situación es que las empresas infractoras siguen ejecutando los contratos cuyo reparto supuso la imposición de la infracción administrativa de competencia con claro perjuicio para el interés general.

En 2017 la Autoridad Catalana resolvió por terminación convencional un expediente en que se analiza una posible infracción de la LDC generada por "una normativa local destinada a regular la distribución de espacios en la Feria de Sant Ermengol (Criterios a seguir para la distribución de espacios en la Feria de Sant Ermengol), aprobada por el Ayuntamiento de la Seu d'Urgell. La ordenanza del Ayuntamiento contenía varios artículos que alteraban "injustificadamente las condiciones de competencia entre las empresas" situando a algunas de ellas "en una posición más ventajosa" favoreciendo a las entidades "que radiquen en el municipio de la Seu d'Urgell y a los expositores que tienen una mayor antigüedad en la participación en la Feria de Sant Ermengol, sin que todo ello sea producto de sus méritos empresariales y, por lo tanto, falsea injustificadamente la competencia en perjuicio de los visitantes/consumidores del citado evento" $"$.

En 2018 la Autoridad Catalana de Competencia (ACCO) dictó una Resolución, APARCAMIENTO SANT JOAN DESPÍ, que analiza unos hechos muy próximos a los previamente expuestos en el asunto de la CNMC y los finaliza por medio de una Terminación Convencional cuyo objeto es paralizar la conducta de manera rápida y eficiente ${ }^{86}$.

En diciembre de 2019, la ACCO dictó una muy interesante resolución en el asunto Radares Meteorológicos ${ }^{87}$. El asunto tiene relevancia, dado que en un asunto de bid rigging se declara responsable (junto con las empresas) al funcionario encargado de organizar el contrato en calidad de facilitador. Resulta peculiar, sin embargo, que no se considere incluida a la administración contratante (que al menos tendría responsabilidad in vigilando respecto del funcionario encargado).

56. De cuanto antecede se deduce que hay un nutrido cuerpo de resoluciones dictadas por numerosas autoridades de competencia españolas que se han mostrado favorables a considerar a los poderes públicos como sujetos activos de las infracciones de competencia no solo a título de autores sino también de facilitadores y no solo actuando como operadores económicos sino también ejerciendo potestades públicas. Es decir, sin limitar a la función de promoción la reacción posible de las autoridades de competencia en los casos en que ésta sea posible.

\section{B. Una jurisprudencia no unánime}

57. Sobre esta cuestión se ha pronunciado el Tribunal Supremo en varias ocasiones. Ya en 2008 el se pronunció sobre la cuestión a raíz del Código Deontológico de la Abogacía que prohibía la cuota litis, lo que había sido calificado por el TDC como una decisión colectiva restrictiva de la competencia ${ }^{88}$. La alta instancia dijo entonces que

"resulta claro que la función de ordenación de las profesiones colegiadas y su regulación deontológica, así como, en concreto, el establecimiento de criterios sobre remuneración, todo ello con carácter vinculante, constituye una potestad de innegable carácter público, sin la cual no podría ser obligatoria para los colegiados (...) la prohibición de la cuota litis en sentido estricto choca frontalmente con lo establecido en el artículo 1.1.a) de la Ley de Defensa de la Competencia que prohíbe la fijación directa o indirecta de precios así como la de otras condiciones comerciales o de servicio. No cabe duda, en efecto,

\footnotetext{
${ }^{85}$ RESOLUCIÓN de la ACCO de 16 de febrero de 2017, Expediente n. ${ }^{\circ}$ 63/2014, FERIA DE SANT ERMENGOL.

${ }^{86}$ Resolución de la Autoritat Catalana de la Competencia de 19 de diciembre de 2018. Expediente 79/2016, APARCAMIENTO SANT JOAN DESPÍ

${ }^{87}$ Resolución de la Autoridad Catalana de Competencia de 23 diciembre de 2019, Expediente 94/2018, Licitaciones Servicio Meteorológico en http://acco.gencat.cat/web/.content/80_acco/documents/arxius/actuacions/20200121_Resolucion-exp.-94.18PUB.pdf.

${ }^{88}$ Sentencia del TS núm. 6610/2008, de 4 de noviembre de 2008, Rec. núm. 5837/2005, relativa a la resolución del TDC de 26 de septiembre de 2002, en el Expte. 528/01, Consejo General de la Abogacía (cuota litis).
} 
que la prohibición de la que se habla supone una fijación indirecta de precios mínimos que impide la libertad por parte del profesional de condicionar su remuneración a un determinado resultado positivo. Supone también y por ello mismo una limitación en cuanto a las condiciones en que se presta el servicio profesional. Por las mismas razones se incumple lo prevenido en la Ley de Colegios Profesionales al determinar que el ejercicio de las profesiones colegiadas se ha de realizar en régimen de libre competencia y sujeto "en cuanto a la oferta de servicios y la fijación de su remuneración" a las previsiones de la Ley de Defensa de la Competencia (artículo 2.1, segundo párrafo) y, que los acuerdos, decisiones y recomendaciones de los Colegios con trascendencia económica han de observar los límites del referido artículo 1 de la Ley de Defensa de la Competencia”

58. En la mencionada Sentencia Vinos de Jerez, crucial también a estos efectos, el TS manifiesta que "sin duda habrá supuestos en que, por estar dirigida la apreciación de una posible vulneración del derecho de la competencia contra un acto administrativo formalmente adoptado, o contra una disposición de carácter general, la vía a seguir por la Comisión Nacional de los Mercados y la Competencia -o, en su caso, por los órganos de las Comunidades Autónomas con atribuciones en materia de defensa de la competencia- será la de la impugnación del acto o disposición ante la Jurisdicción ContenciosoAdministrativa conforme a lo previsto en los artículos 12.3 y 13.2 de la Ley 15/2007. Pero la capacidad de reacción de las autoridades de defensa de la competencia no puede quedar reducida a esa vía impugnatoria; sobre todo cuando se trata de actuaciones materiales como las que describe la resolución de la Comisión en el caso que estamos examinando ${ }^{\mathbf{8 9}}$."

De las citadas afirmaciones debe deducirse que el Tribunal Supremo no plantea las vías de la impugnación y sanción como excluyentes entre sí. De la afirmación del Tribunal se deduce, por el contrario, que será necesario realizar un análisis caso por caso ("sin duda habrá supuestos en que") y también que la capacidad de reacción por la vía de la promoción de la competencia no excluye la vía de la defensa. No en vano el Tribunal mantiene que la capacidad de reacción "no puede quedar reducida" a la primera vía "sobre todo" cuando se trata de actuaciones como las allí analizadas.

59. Sin embargo, poco después, en su sentencia de 27 de julio de 2017, el Tribunal manifestó algo diferente al entender que, desde el momento en que la LDC atribuye a la autoridad de competencia la posibilidad de impugnación, desaparece la capacidad de estos organismos de "considerar ya por su propia autoridad disconformes a derecho los actos y disposiciones generales de rango inferior a la ley de las Administraciones Públicas" ".90. Afirma el Tribunal que la capacidad de impugnación no solo genera una facultad para la autoridad de competencia sino que "paradójicamente, (crea) una cierta carga pues, de no impugnarlos, la Comisión Nacional de la Competencia no podrá desconocer por otras vías la presunción de validez de los actos administrativos de las diferentes Administraciones Públicas (ella misma es un órgano administrativo, no jurisdiccional) ni considerar, por su propia autoridad, disconformes a derecho las disposiciones reglamentarias".

Todo ello no implica que las administraciones no puedan generar problemas de competencia sino que los mismos tan solo podrán ser abordados desde la perspectiva de defensa cuando la actuación de la Administración Pública se produce no en virtud de sus atribuciones de imperium sino en su calidad de operador económico que interviene en el mercado y presta sus servicios dentro de un marco de concurrencia con otros agentes.

El TS resolvía en contra de una resolución de la Autoridad Catalana de Competencia que sancionaba a un Colegio Profesional por los acuerdos contrarios al art. 1 LDC consistentes en la introducción

${ }^{89}$ Sentencia del Tribunal Supremo de 18 de julio de 2016, Recurso 2946/2013, (ECLI: ES:TS:2016:3525), dictada respecto de la Resolución de 6 de octubre de 2011 de la CNC en el expediente S/167/09 productores de uva y vino de Jerez accesible en https://www.cnmc.es/expedientes/s016709.

${ }^{90}$ Sentencia del TS núm. 3131/2017, de 27 de julio, Rec. núm. 965/2015, relativa a la resolución del Tribunal Catalán de Defensa de la Competencia de 25 de julio de 2012, Expte. ACCO 25/2010, COAPI Barcelona. Esta sentencia también se ampara en otras anteriores, muy especialmente en la sentencia del TS núm. 3141/2013, de 14 de junio, Rec. núm. 3568/2010, relativa a la Resolución de la CNC de 3 de marzo de 2009, Expte. 650/08, Funerarias Baleares, de forma que fija jurisprudencia en este sentido. 
en los Estatutos, Reglamento de Régimen Interno y Reglamento de turno de valoraciones, de restricciones de la competencia relativas al acceso y ejercicio de la profesión y a la fijación de honorarios mínimos. El Tribunal considera que es necesario hacer una distinción entre la adopción de decisiones manifestadas en acuerdos de los órganos de gobierno del Colegio trasladados a la normativa colegial y la recomendación colectiva concretada en la elaboración de una lista de honorarios. Las primeras (normas colegiales y las decisiones previas a su adopción) tendrían naturaleza pública y habrían sido adoptadas gracias a la atribución de competencias de los poderes públicos.

Sin embargo, la recomendación colectiva, debía ser considerada en sí misma (con independencia de que hubiera sido posteriormente incorporada a los estatutos), como una recomendación colectiva que no puede ampararse en las funciones de carácter público del Colegio. En este caso el Colegio estaría actuando como representante asociativo de unos profesionales y en defensa de sus intereses. Por ello estaría actuando como operador económico y por lo tanto su actuación puede constituir una infracción.

60. El análisis jurisprudencial no puede desconocer la visión ofrecida en este punto por el Tribunal de Justicia de la Unión Europea.

En respuesta a una cuestión prejudicial, el Tribunal analiza un reglamento adoptado por un colegio profesional que imponía una serie de obligaciones relativas a la formación de los colegiados ${ }^{91}$. El TJUE concluyó que el Colegio creando estas normas se configuraba como un órgano regulador de una profesión y que la conducta podía ser calificada como una decisión colectiva tipificada en el artículo 101 del TFUE. En concreto:

44. Aun suponiendo que dicho Reglamento no tenga influencia directa en la actividad económica de los propios expertos contables, como parece sugerir el órgano jurisdiccional remitente en su tercera cuestión, esta circunstancia no podría por sí sola excluir del ámbito de aplicación del artículo 101 TFUE una decisión de una asociación de empresas.

45. Una decisión de este tipo puede, en efecto, impedir, restringir o falsear el juego de la competencia en el sentido del artículo 101 TFUE, apartado 1, no sólo en el mercado en que los miembros de un colegio profesional ejercen su actividad, sino también en aquel otro en el que el propio colegio desarrolla una actividad económica.

46. En segundo lugar, cuando adopta un reglamento como el aquí controvertido, un colegio profesional como la OTOC no ejerce prerrogativas del poder público, sino que se configura más bien como el órgano regulador de una profesión cuyo ejercicio constituye, por otro lado, una actividad económica.

\section{Análisis de las posibles soluciones}

61. Como se ha podido observar, la jurisprudencia no es unánime respecto de la relación que debería plantearse en los supuestos en que una conducta llevada a cabo por un poder público pudiera ser susceptible de impugnación y de infracción. Por ello, en aras de enriquecer la discusión, recogemos a continuación algunas visiones de los pros y contras de cada una de las posibles interpretaciones.

62. Como hemos visto, ante una conducta que puede constituir una limitación a la competencia y puede ser objeto de impugnación, la autoridad de competencia tendría varias posibilidades de reacción.

Podría sin duda emplearse la vía de la promoción ex ante, realizando recomendaciones a las administraciones para que opten por soluciones que garanticen el acceso al mayor número posible de

\footnotetext{
${ }^{91}$ Sentencia de 28 de febrero de 2013, en el asunto C-1/12, OTOC Esta cuestión prejudicial tenía por finalidad analizar la compatibilidad con el artículo 101 TFUE del Regulamento da Formação de Créditos (Reglamento sobre la obtención de créditos) adoptado en mayo de 2007 por la Cámara del Colegio de expertos contables (OTOC), en el marco de un litigio de la autoridad portuguesa de competencia, que imponía a todos los expertos contables la obligación de obtener determinada formación dispensada por la OTOC o aprobada por ésta, y otorgaba la decisión a la OTOC sobre qué organismos de formación estaban autorizados para efectuar acciones de formación. No se trataba por tanto del propio estatuto colegial, sino de un reglamento adoptado en desarrollo de aquel.
} 
operadores y no generen discriminación ni otros problemas de competencia. De este modo se promovería la posibilidad de que los ciudadanos se beneficien de las ventajas que se derivan de la competencia entre los operadores (en precios, prestaciones o calidad del servicio recibido).

En segundo lugar, también existe la posibilidad (aún dentro de la vía de la promoción de la competencia, pero en este caso ex post) de impugnar las decisiones administrativas (incluyendo las normas con rango inferior a la Ley).

Sin embargo, esta posibilidad tiene en nuestro ordenamiento jurídico una limitación temporal acusada, dado que los plazos de impugnación son, en general, de dos meses. Transcurrido ese plazo, las posibilidades de impugnación quedan limitadas (siendo tan solo posible impugnar los posibles actos de ejecución).

Por esta razón limitar la vía de la defensa en estos supuestos por el hecho de que una impugnación hubiese sido posible, circunscribe sin base jurídica alguna las posibilidades de reacción de la Administración para actuar de manera eficaz ante restricciones de la competencia que generan un desvalor en el mercado (empresa denunciante) y que reducen el requerido estándar de protección del interés general (ciudadanos que se beneficiarían de la competencia entre los posibles operadores entrantes) ${ }^{92}$.

Además, si se optase por esta interpretación, en el caso de que una autoridad de competencia no tuviese conocimiento de las barreras de entrada en plazo para la impugnación, no existiría vía alguna para compeler a la Administración que ha establecido las barreras injustificadas a eliminarlas durante la vida del contrato. Ello situaría a los adjudicatarios en una posición de indebida ventaja durante un período que dependiendo de los supuestos puede ser prolongado y, lo que es más grave, privaría a los operadores entrantes y a los ciudadanos de derechos amparados por el ordenamiento.

63. La exigida eficacia en la actuación de la Administración -y en consecuencia todas las administraciones y entes públicos, así como de las autoridades de competencia - impide esta interpretación limitativa de las capacidades abiertas por la Ley a las autoridades de competencia.

La misma no podría considerarse conforme con el artículo 103.1 de la Constitución Española que consagra el principio de eficacia y pleno sometimiento a la Ley y al Derecho en la actuación administrativa ni tampoco con el artículo 41 de la Carta de Derechos Fundamentales de la Unión Europea que recoge el derecho de los ciudadanos a una buena administración.

\section{Conclusión}

Las ventajas que la competencia genera en la sociedad son profundas y por ello requieren de un sistema institucional fuerte e independiente de los poderes públicos y económicos que, con determinación y seguridad jurídica, garantice la aplicación de los principios inspiradores de este régimen jurídico.

Cada una de las herramientas previstas en el ordenamiento para verificar las limitaciones a la competencia que se pueden generar por un poder público tiene ventajas que las hacen más o menos adecuadas dependiendo de los supuestos.

Sin embargo, la limitación de las funciones de defensa de la competencia cuando sea posible el recurso a la impugnación que se impondría si se asienta la jurisprudencia reciente mencionada carecería de un fundamento normativo claro e iría en contra del efecto útil del Derecho de la competencia y la requerida eficiencia en la aplicación de los principios de competencia. Esta interpretación vendría a cristalizar, por una mera limitación procedimental, restricciones que generan efectos negativos para el interés general.

Por ello podemos concluir que la vía de la promoción es útil y eficaz para analizar las limitaciones a la competencia de los poderes públicos y puede considerarse imprescindible, pero en algunos casos no resulta suficiente para alcanzar los objetivos de protección del bienestar social pretendidos. En esos supuestos la vía de la defensa de la competencia, que implica considerar a los poderes públicos res-

${ }^{92}$ A.Fels/ W.NG, "Rethinking Competition Advocacy in Developing Countries", en D.Sokol/ T.ChEng/I.Lianos, Competition Law and Development, Stanford University Press, England, 2013, pág. 182 a 198. 
ponsables de la comisión de infracciones de competencia, es la más o incluso la única vía para conseguir la adecuada protección del interés general.

Considerar que no cabe defensa de la competencia en los supuestos en que pueden realizarse impugnaciones puede resultar contrario al efecto útil del derecho de la competencia. Por ello ambas vías de actuación deben necesariamente considerarse herramientas complementarias y en ningún caso excluyentes. 